\title{
Immune and Neuroendocrine Mechanisms of Stress Vulnerability and Resilience
}

\author{
Caroline Ménard ${ }^{1}$, Madeline L Pfau ${ }^{1}$, Georgia E Hodes ${ }^{1}$ and Scott J Russo ${ }^{\star, 1}$ \\ ${ }^{1}$ Fishberg Department of Neuroscience and the Friedman Brain Institute, Icahn School of Medicine at Mount Sinai, New York, \\ NY, USA
}

\begin{abstract}
Diagnostic criteria for mood disorders including major depressive disorder (MDD) largely ignore biological factors in favor of behavioral symptoms. Compounding this paucity of psychiatric biomarkers is a need for therapeutics to adequately treat the 30-50\% of MDD patients who are unresponsive to traditional antidepressant medications. Interestingly, MDD is highly prevalent in patients suffering from chronic inflammatory conditions, and MDD patients exhibit higher levels of circulating proinflammatory cytokines. Together, these clinical findings suggest a role for the immune system in vulnerability to stress-related psychiatric illness. A growing body of literature also implicates the immune system in stress resilience and coping. In this review, we discuss the mechanisms by which peripheral and central immune cells act on the brain to affect stress-related neurobiological and neuroendocrine responses. We specifically focus on the roles of pro-inflammatory cytokine signaling, peripheral monocyte infiltration, microglial activation, and hypothalamic-pituitary-adrenal axis hyperactivity in stress vulnerability. We also highlight recent evidence suggesting that adaptive immune responses and treatment with immune modulators (exogenous glucocorticoids, humanized antibodies against cytokines) may decrease depressive symptoms and thus represent an attractive alternative to the current antidepressant treatments.

Neuropsychopharmacology Reviews (20 I7) 42, 62-80; doi: 10.1 1038/npp.2016.90; published online 6 July 2016
\end{abstract}

\section{INTRODUCTION}

One out of five people will suffer from a mood disorder during their lifetime (Kessler et al, 2005; Kessler et al, 1993). Major depressive disorder (MDD), the most prevalent mood disorder (6.7\%) (Kessler et al, 2005), is the leading cause of worldwide disability (Lopez and Murray, 1998). Core symptoms of MDD include depressed mood, irritability, anhedonia (defined as the reduced ability to experience pleasure from previously rewarding activities), difficulty concentrating, and disrupted appetite and sleep habits (Krishnan and Nestler, 2008). Several clinical studies report a high prevalence of MDD comorbidity with inflammatory diseases including cardiovascular diseases, diabetes, metabolic disorders, asthma, and rheumatoid arthritis, as presented in Table 1 (Fenton and Stover, 2006; Maes et al, 2011; Moussavi et al, 2007). Underscoring these data is the finding that subsets of MDD patients display higher levels of inflammatory markers such as cytokines and circulating leukocytes (Dowlati et al, 2010; Lanquillon et al,

${ }^{*}$ Correspondence: Professor SJ Russo, Fishberg Department of Neuroscience, Icahn School of Medicine at Mount Sinai, 1425 Madison Avenue, New York, NY 10029, USA. Tel: +1 212659 8625, Fax: +1212 659 8574, E-mail: scott.russo@mssm.edu

Received 5 March 2016; revised 17 May 2016; accepted 18 May 2016; accepted article preview online 13 June 2016
2000; Maes, 1995; Maes et al, 1995a; Maes et al, 1992; Maes et al, 1995b). This observation informed the macrophage theory of depression, which argues that overactive cytokine secretion by macrophages (stimulated by allergens, chronic disease, estrogen, etc) drives the neuroendocrine disruptions observed in depressed individuals (Smith, 1991). Subsequent work has identified enhanced peripheral inflammation in post-traumatic stress disorder (PTSD) (Baker et al, 2001; Gill et al, 2008; Newton et al, 2014; Passos et al, 2015) and bipolar disorder (Fiedorowicz et al, 2015; Goldstein et al, 2009; Kalelioglu et al, 2015; Uyanik et al, 2015).

Prolonged stress induces neuroimmune and neuroendocrine responses, and individual differences in these responses likely shape behavioral vulnerability and resilience (Charney, 2004; Hodes et al, 2015a). In some individuals, overactive, unresolved stress responses may increase stress vulnerability and ultimately the development of mood disorders (Charney, 2004). However, most individuals mount adaptive coping mechanisms that promote resilience in the face of stress (Pfau and Russo, 2015; Russo et al, 2012). Here, we provide an overview of insights from human and rodent studies highlighting a role for the immune system in the development of stress vulnerability $v s$ resilience and the pathogenesis of mood disorders with a focus on MDD. 
TABLE 1 Comorbidity of MDD with Inflammatory Diseases

\begin{tabular}{|c|c|c|}
\hline Diseases & Prevalence of depression & References \\
\hline \multicolumn{3}{|l|}{ Healthy } \\
\hline General population & $6.7 \%$ & Kessler et al, 2005 \\
\hline \multicolumn{3}{|l|}{ Autoimmune diseases } \\
\hline Multiple sclerosis & $23.7-50 \%$ & Marrie et al, 2015; Siegert and Abernethy, 2005 \\
\hline Systemic lupus & $10.8-44 \%$ & Ainiala et al, 200 I; Nery et al, 2007 \\
\hline \multicolumn{3}{|l|}{ Neurodegenerative disorders } \\
\hline Alzheimer's disease & $30-50 \%$ & Lee and Lyketsos, 2003; Zhao et al, 2016 \\
\hline Parkinson's disease & $7-76 \%$ & Veazey et al, 2005; Bomasang-Layno et al, 2015 \\
\hline Huntington's disease & $48.2 \%$ & Wetzel et al, 201 I \\
\hline \multicolumn{3}{|l|}{ Metabolic disorders } \\
\hline Chronic obstructive pulmonary disorders & $6-42 \%$ & Maurer et al, 2008 \\
\hline HIV & $5-42 \%$ & Cruess et al, 2003; Nanni et al, 2015 \\
\hline Asthma & $7.6-20.2 \%$ & Jiang et al, 2014 \\
\hline
\end{tabular}

This table was adapted with from Iwata et al, 2013 and updated to include the recent clinical findings.

\section{DEFINITION OF STRESS VULNERABILITY VS RESILIENCE}

The adaptive physiological response to acute stress is crucial for survival in life-threatening situations. However, the failure to resolve a physiological stress response upon cessation of an acute stressful event may create a deleterious allostatic load, leading to stress vulnerability and enhanced risk of mood disorders (Charney, 2004; Goldstein and McEwen, 2002). Allostatic load is defined as the physiological and psychological burden placed upon the brain and body by stress (Goldstein and McEwen, 2002). Conversely, resilience is defined as an integrated process involving multiple peripheral and central mechanisms that promotes an appropriate, non-pathological stress response (Charney, 2004; Pfau and Russo, 2015; Russo et al, 2012). Maladaptive neurobiological responses associated with mood disorders have been studied extensively for decades. Resilience was first described in at risk children in the 1970s (Garmezy, 1971; Masten, 2001) and has inspired increasing interest as a means to understand mood disorder etiology and identify novel strategies for prevention and treatment. A greater understanding of resilience biology is important, given that only $30 \%$ of patients completely remit following treatment with current first-line antidepressant therapies, making MDD a chronic, recurrent condition for many sufferers (Krishnan and Nestler, 2008). Furthermore, $30-50 \%$ of depressed patients are unresponsive to any approved antidepressant treatment (Krishnan and Nestler, 2008). This lack of efficacy suggests that current treatments fail to address causal or secondary pathological responses, preventing complete remission. We propose here that circulating inflammatory molecules and/or exacerbated immune responses, neither of which are primary targets of current antidepressant treatments, likely contribute to both the development of mood disorders and resistance to treatment.

\section{THE ROLE OF IMMUNE SYSTEM IN CHRONIC PSYCHOLOGICAL STRESS RESPONSE}

Stress precipitates inflammatory events in both the central nervous system (CNS) and peripheral immune system that are relevant to behavioral vulnerability and resilience. Here, we will overview the major components of the immune system (innate and adaptive) before detailing the effects of stress on immune cells and cytokines, both peripherally and centrally.

\section{The Innate Immune System}

Innate immune cells (monocytes, granulocytes, macrophages, dendritic cells and innate lymphocytes) react to pathogens or injury by mounting rapid and effective responses (Hodes et al, 2015a; Rosenblat et al, 2014). They are equipped with receptors recognizing pathogen-associated molecular patterns or danger-associated molecular patterns (Frank et al, 2015; Portou et al, 2015). Activation of these receptors can induce signaling cascades that stimulate the release of inflammatory mediators such as prostaglandins, leukotrienes, bradykinin, histamines, and serotonin 
(Rosenblat et al, 2014). These molecules produce a local inflammatory response comprising vasodilatation, pain receptor stimulation, and release of pro-inflammatory cytokines. Pro-inflammatory cytokines such as interleukin1-beta (IL-1 $\beta$ ), IL-6, and tumor necrosis factor-alpha (TNF $\alpha$ ) are released by tissue-resident dendritic cells and macrophages (Hodes et al, 2015a; Rosenblat et al, 2014), leading to the recruitment of immature Ly $6 c^{\text {high }}$ monocytes and neutrophils. Recruited monocytes can further differentiate into phagocytic macrophages to enhance inflammatory processes or promote resolution of inflammation (Ginhoux and Jung, 2014; Shi and Pamer, 2011). As in trauma-related injury, psychological stress can induce monocytosis, defined as an increase in the number of monocytes circulating in blood (Ginhoux and Jung, 2014). Although the immune response to stress can be adaptive in the short term, chronic psychological stress can produce sustained, unresolved inflammation and leukocytosis, which are hallmark symptoms of depression (Maes et al, 1992).

\section{The Adaptive Immune System}

Adaptive immune cells ( $\mathrm{T}$ and B lymphocytes) can induce an immune response in secondary lymphoid organs such as lymph nodes and spleen. Adaptive immunity refers to the storage of an immunological memory after an initial response to a pathogen that then enhances future responses to that pathogen (for review, refer to Mueller and Mackay, 2016). Effector memory $T$ cells are abundant in nonlymphoid tissues and circulate in the bloodstream, while another subset of central memory $\mathrm{T}$ cells is predominant in secondary lymphoid organs (lymph nodes and spleen) in the absence of inflammation. Memory $\mathrm{T}$ cells become activated upon presentation of a previously encountered specific antigen by an antigen-presenting cell. Tissueresident memory $\mathrm{T}$ cells respond rapidly to local pathogen re-encounter initiating cytokine release and recruitment of natural killer and dendritic cells (Mueller and Mackay, 2016). It is thought that the adaptive immune system may store the immunological memory of a stressor, thereby enabling a protection against future similar stress exposure (Lewitus and Schwartz, 2009a) and possibly the establishment of mood disorders (Miller, 2010).

\section{Stress and Peripheral Immune Cells}

Cells of the innate immune system. Numerous recent studies suggest that chronic stress mobilizes the innate immune system, stimulating enhanced proliferation and release of inflammatory Ly $6 c^{\text {high }}$ monocytes and neutrophils (Figure 1a). Powell et al (2013) utilized repeated social defeat (RSD) to investigate the effects of stress on leukocyte biology. In the RSD paradigm, a novel, aggressive CD-1 mouse is introduced into a home cage of three C57BL/6 mice for $2 \mathrm{~h}$ over six consecutive nights, disrupting the social hierarchy of the cage and eliciting submissive behaviors. The authors found that RSD increases monocyte and granulocyte progenitor cells within bone marrow and induces blood monocytosis and granulopoiesis. They further identified a stress-induced, $\beta$-adrenergic receptor signaling-dependent leukocyte transcriptional profile that favored the release of Ly $6 c^{\text {high }}$ monocytes and Ly $6 c^{\text {intermediate }}$ granulocytes into circulation. This occurs via enhanced expression of proinflammatory genes and myeloid lineage commitment genes accompanied by decreased expression of terminal myeloid differentiation genes (Powell et al, 2013). These findings were mirrored in human subjects of low socioeconomic status (SES), a form of chronic social stress that can activate the sympathetic nervous system. Low SES subjects had higher relative and absolute counts of monocytes in blood and displayed a leukocyte transcriptional profile favoring monocytosis and $\beta$-adrenergic signaling (Powell et al, 2013). Heidt et al (2014) reported similar findings using rodent chronic variable stress (CVS), in which mice were subjected to 3 weeks of varying, unpredictable stressors (cage tilt, wet bedding, social isolation, cage crowding, and constant illumination). Mice exposed to CVS had more monocytes and neutrophils in blood and bone marrow than did home cage controls, an effect dependent on $\beta_{3}$-adrenergic receptor signaling (Heidt et al, 2014). Stress affects not only cell number but also cell reactivity in the innate immune system. Following exposure to RSD, splenic macrophages of stressed mice exhibit enhanced release of TNF $\alpha$ and IL-6 in response to treatment with lipopolysaccharide (LPS, a bacterial endotoxin and toll-like receptor (TLR4) agonist), an effect mediated by stress-induced glucocorticoid (GC) resistance (Avitsur et al, 2005). Interestingly, Avitsur et al (2001) reported individual differences in splenocyte GC resistance related to social hierarchy. Submissive mice were more likely to develop splenocyte GC resistance following RSD than were control and dominant mice, suggesting that pre-existing differences in social status may underlie susceptibility $v s$ resilience to stress-induced inflammation. Although these studies inform our understanding of the effect of stress on the innate immune system, more research is necessary to determine the innate immune profile of resilience.

Cells of the adaptive immune system. As mentioned above, the adaptive immune system is thought to play a protective role by 'inoculating' an individual against repeated stressors, thereby promoting resilience (Figure 1e and g). Lewitus et al (2009b) showed that T-cell-dependent immunization with a weak agonist of a CNS-specific myelin-derived peptide before exposure to chronic mild stress ameliorated subsequent depression-like behaviors in rats (Figure 1g). Accordingly, in a predator odor challenge that is considered a model of PTSD, mice overexpressing autoreactive $\mathrm{T}$ cells exhibit resilience to the stressful episode (Cohen et al, 2006). Conversely, T-cell-deficient mice are more vulnerable to stress, displaying enhanced social avoidance and acoustic startle response (Cohen et al, 2006). Inoculation with a single population of $\mathrm{T}$ cells reactive to CNS-associated selfantigens (cells capable of homing to the CNS) was sufficient 
to protect T-cell-deficient mice and promote resilience (Cohen et al, 2006). These preclinical studies suggest that, like inoculation of a weak antigen for infectious disease vaccination, mild activation of the adaptive immune system before stress exposure can confer a relative protection against stress-related psychiatric disorders.
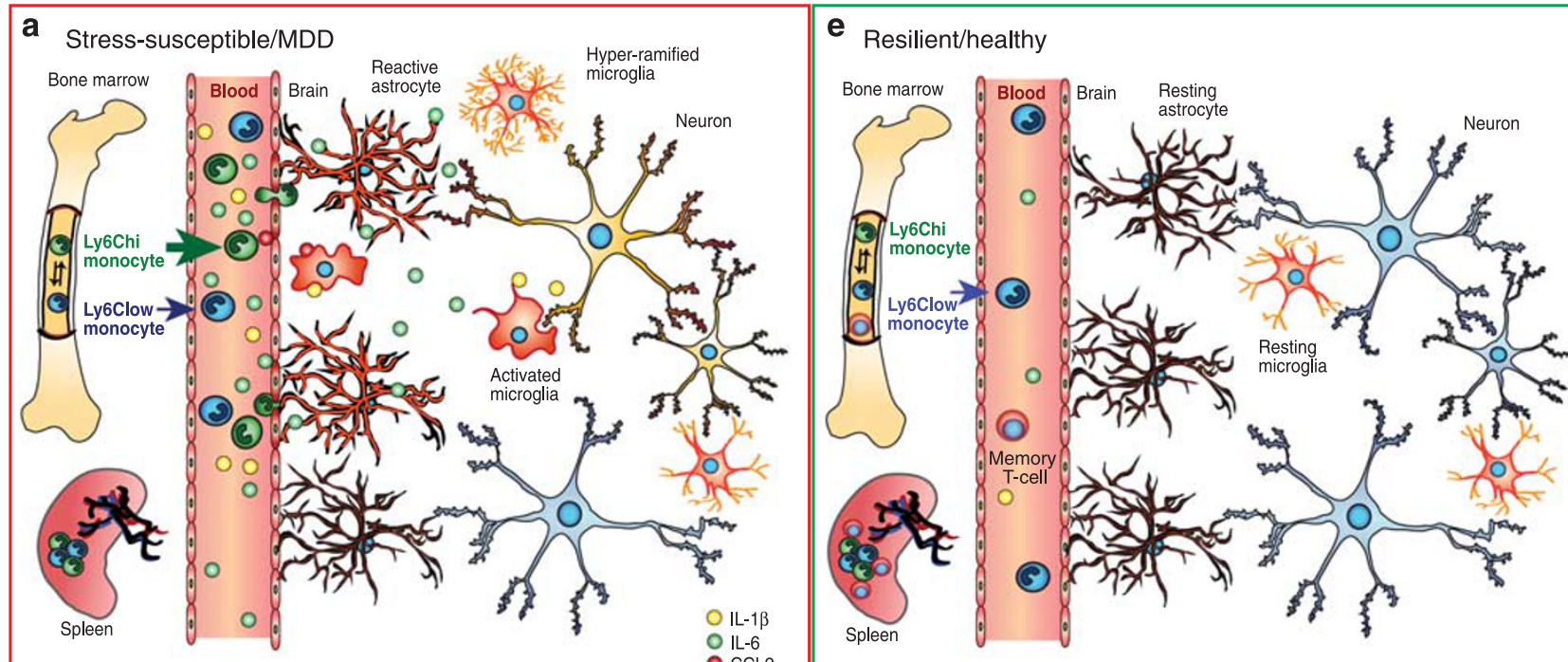

b High pro-inflammatory cytokine levels

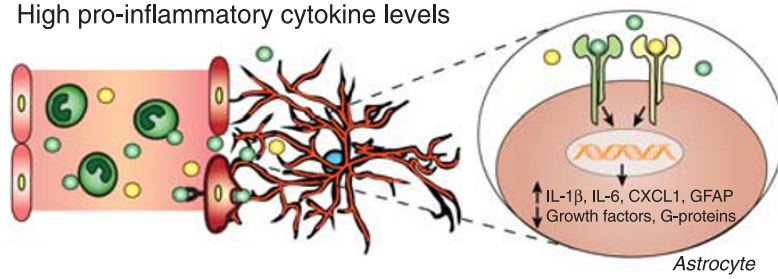

f Low pro-inflammatory cytokine levels

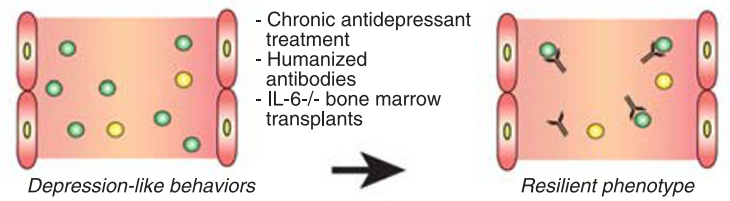

C Monocyte infiltration
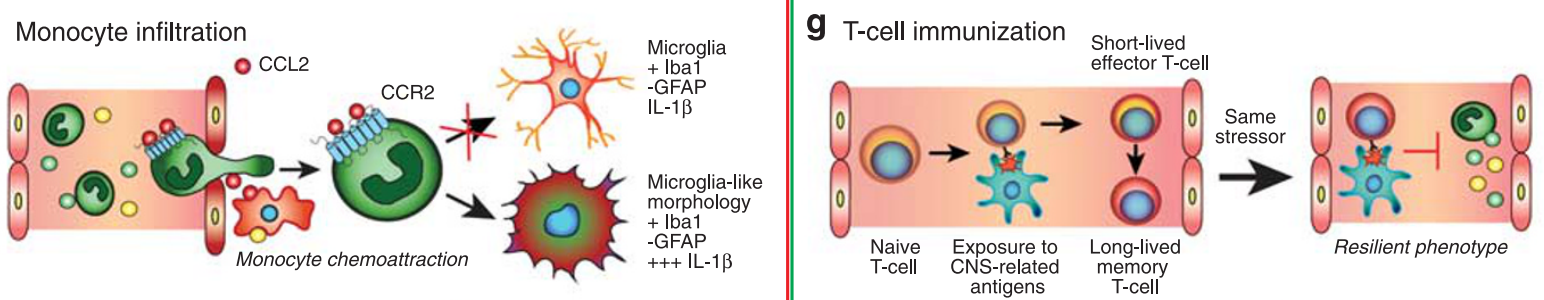

d Microglia activation

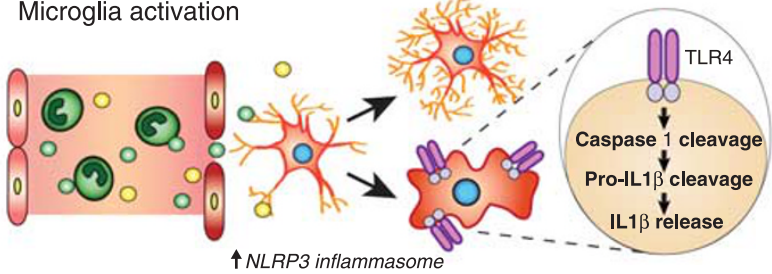

h Microglia hyporeactivity

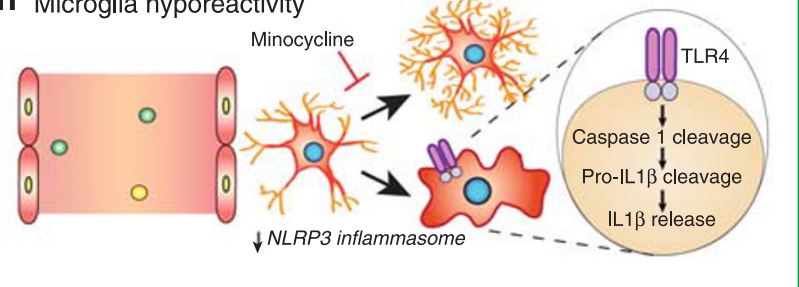

Figure 1. Immune mechanisms of stress vulnerability and resilience. (a) Circulating levels of pro-inflammatory cytokines (IL-1 $\beta$ and IL-6) are elevated in the blood of stress-susceptible animals and MDD patients altering neuronal, astrocytic and microglial functions. (b) Pro-inflammatory cytokines activate receptors at the cell surface of reactive astrocytes leading to enhanced expression of structural GFAP and release of inflammatory mediators and reduced expression of G-protein effectors and growth factors. (c) Activated microglia can release chemokine ligand 2 (CCL2) in the blood attracting patrolling immature Ly6C high monocytes through binding of CCL2 to chemokine receptor 2 (CCR2). These monocytes can cross the blood-brain barrier and penetrate into the brain, particularly in stress-related brain regions expressing high levels of pro-inflammatory cytokine IL-1 $\beta$, where they differentiate into phagocytic macrophages displaying a microglia-like morphology as assessed with microglia marker lba1. (d) Activation of the NLRP3 inflammasome, constitutively expressed in macrophages and microglia, through Toll-like receptor 4 (TLR4) binding initiate pro-caspase-1 and pro-IL-1 $\beta$ cleavage leading to the secretion of pro-inflammatory IL-1 $\beta$. Chronic stress also induces microglia hyper-ramification in rodent models of depression. (e) On the other hand, resilient animals do not display exacerbated immune responses following acute or chronic stressors. (f) In fact, lowering circulating pro-inflammatory cytokines levels by antidepressant treatment, humanized antibodies or IL-6 ${ }^{-/}$bone marrow transplants reverse depression-like behaviors and promote a resilient phenotype. (g) Immunization through production of long-lived memory T-cell after exposure to CNS-related antigens could even help to build appropriate adaptive immune responses to future stressors. (h) Lower microglia reactivity and NLRP3 inflammasome activation could also be associated with resiliency as reduction of microglial activity by administration of the inhibitor minocycline abolishes the pro-ramifying effect of stress and reverses depression-like behaviors. 
TABLE 2 Studies Related To Cytokines in Mood Disorders

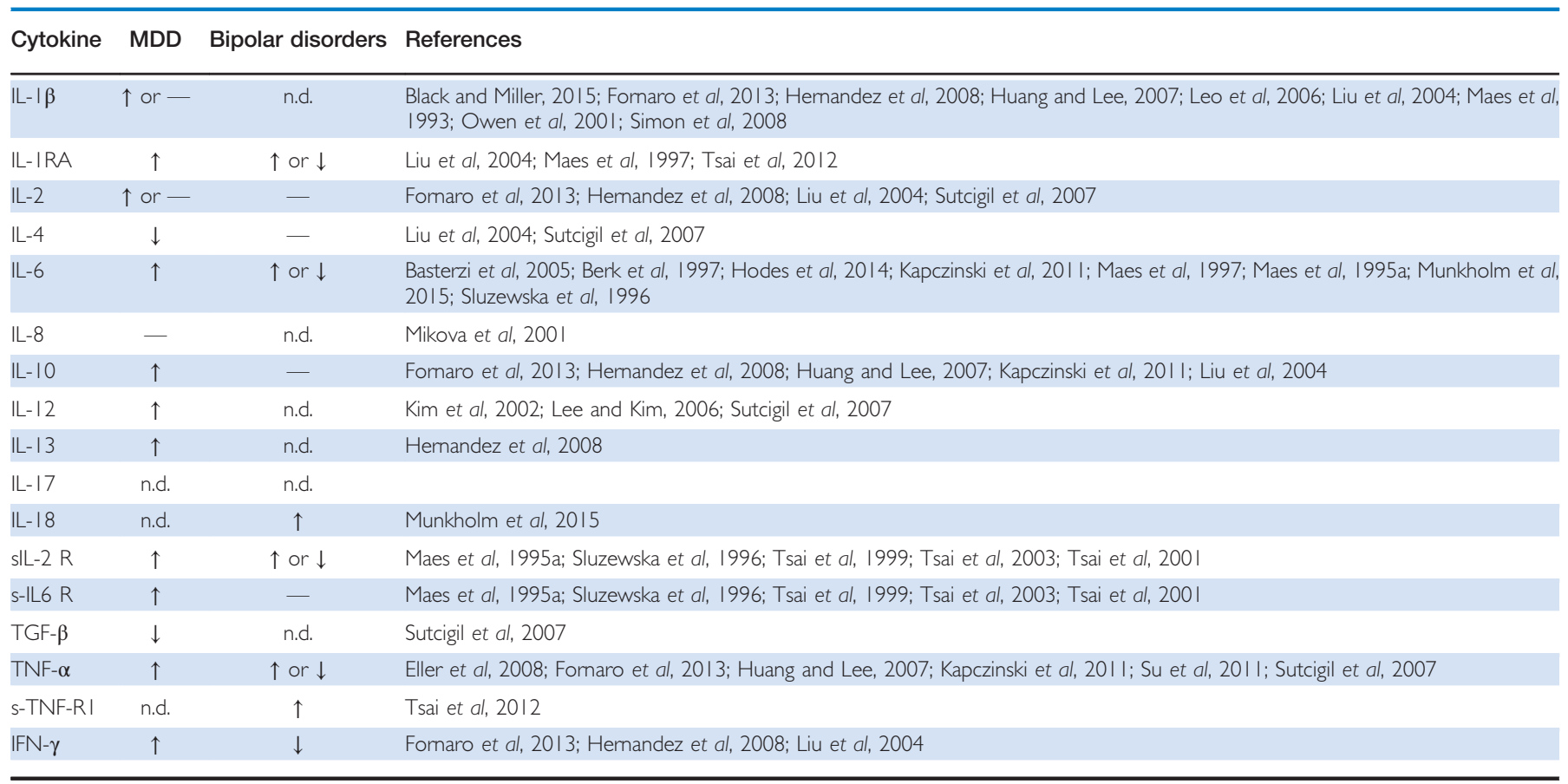

Supporting the adaptive immune system stress inoculation theory, a recent study reported that transplantation of lymph node cell suspensions from previously stressed mice into Rag2 knockout mice that lack mature lymphocytes induces a resilient phenotype characterized by prosocial behavior and reduced anxiety (Brachman et al, 2015). Transplanted mice displayed reduced pro-inflammatory cytokine levels in peripheral blood, while their microglia, the resident immune cells of the brain, seemed to shift toward an antiinflammatory profile (Brachman et al, 2015). Despite these intriguing findings, far more work is needed to fully understand the role of adaptive immune cells in stress susceptibility and resilience.

Peripheral cytokines and depression. A potential causal link between MDD and inflammation was first revealed when clinicians reported psychiatric complications in a high percentage of patients undergoing long-term interferon- $\alpha$ therapy to control chronic viral hepatitis (Conversano et al, 2015; Renault et al, 1987). In line with these findings, a large body of correlative evidence from clinical studies (Table 2) (Dowlati et al, 2010; Fagundes et al, 2013; Lanquillon et al, 2000; Maes et al, 1995a), suggests that depressed individuals have higher levels of circulating pro-inflammatory cytokines such as IL-1 $\beta$, IL-6 (Figure 1b) and TNF $\alpha$. Increased proinflammatory cytokines have also been reported in rodent models of depression-like behavior (Figure 1b) (Grippo et al, 2005; Hodes et al, 2014). Moreover, systemic administration of IL- $1 \beta$, TNF $\alpha$, or LPS promotes the expression of proinflammatory cytokine genes and proteins in the brain (Laye et al, 1994; Quan et al, 1999; van Dam et al, 1992) and induces sickness behaviors such as social withdrawal, loss of appetite, decreased motor activity, and cognitive deficits in rodents (Dantzer et al, 2008). However, it is important to note that, because the behavior is directly tied to LPS- or cytokine-induced inflammatory activation and subsides following a return to baseline, behavioral changes are considered sickness behavior rather than depression-like behavior. Interestingly in humans, systemic LPS injection resulted in greater feelings of social isolation in women than men (Moieni et al, 2015). Although there were no sex differences in circulating levels of cytokines induced by LPS, the increased feelings of social isolation correlated with circulating levels of IL- 6 and TNF $\alpha$ only in females.

Our group recently reported that differences in the peripheral immune system, notably the number of circulating leukocytes and leukocyte IL-6 release following LPS stimulation, predicts susceptibility or resilience to chronic social defeat stress (CSDS) in mice (Hodes et al, 2014). In this model, repeated social and physical subordination by a physically larger, aggressive CD-1 mouse produces depression-like behaviors, including anhedonia and social avoidance, in the majority of experimental mice-termed stress-susceptible (Golden et al, 2011; Krishnan et al, 2007). However, paralleling resilience to marked stress in humans, not all mice become susceptible and develop a depressive phenotype. This subpopulation of mice behaviorally resilient to CSDS behaves similarly to unstressed controls (Golden et al, 2011; Krishnan et al, 2007). CSDS is a useful animal model to explore stress-induced neurobiological and neuroimmune changes associated with susceptibility and resilience (Hodes et al, 2015a; Menard et al, 2016). Following a single exposure to an aggressor, IL-1 $\beta$ and IL-6 levels were significantly elevated two-fold and nine-fold, respectively, in 
the blood of mice that subsequently became susceptible compared with mice that ultimately became resilient (Figure 1b) (Hodes et al, 2014). Circulating levels of IL-6 were still elevated 48 hours after the last defeat in susceptible mice and remained elevated a month later. To further explore the role of peripheral IL-6 in stress vulnerability, hematopoietic stem cells from stress-susceptible or IL-6 knockout $\left(I L-6^{-1-}\right)$ mice were transplanted into wild-type mice previously subjected to irradiation to eliminate their native peripheral immune system. Stress-susceptible bone marrow chimeras exhibited social avoidance after subthreshold defeat, a paradigm that is normally not sufficient to induce depression-like behaviors (Hodes et al, 2014). Conversely, $I L-\sigma^{-1-}$ chimeras and mice treated with a systemic IL-6 monoclonal antibody demonstrated enhanced resilience to CSDS (Figure 1f) (Hodes et al, 2014). It is important to note that the level of resilience reached by $I L-\sigma^{\prime-}$ chimeras was similar to that of whole body IL-6 knockout mice, suggesting a prominent role for peripheral IL-6 in the development of stress susceptibility (Hodes et al, 2014). In line with the data obtained in mice, IL-6 levels were elevated in the blood of chronically depressed patients resistant to antidepressant treatment (Hodes et al, 2014).

A subsequent study highlighted a role for pro-inflammatory cytokines in the development of stress vulnerability $v s$ resilience in other animal models of depression. Yang et al (2015) showed that peripheral IL-6 is higher in rats displaying learned helplessness (LH) behavior. In this model, experimental animals are exposed to uncontrollable stress in the form of inescapable foot shock for 2 days. On the third day, rodents are subjected to foot shock in a two-wayconditioned avoidance test, in which they can choose to avoid the stressor through an easy escape mechanism. Animals who fail to escape the controllable stressor are categorized as susceptible and show a broad range of behavioral, physiological and hormonal changes associated with depression (Chourbaji et al, 2005; Maier, 1990). As in CSDS, LH can be reversed by chronic, but not acute, antidepressant treatment (Berton et al, 2006; Slattery and Cryan, 2014; Menard et al, 2016).

The aforementioned results, supported by clinical studies in depressed patients, suggest that stress-induced cytokine release may play an important role in the pathogenesis of depression (for review, refer to Miller and Raison (2015)). High levels of circulating inflammatory mediators may affect the brain reward circuitry leading to the establishment of depressive behaviors (Felger et al, 2015b). However, the effects of antidepressant treatment on inflammatory cytokine levels have been contradictory in humans with reported decreased level (Mutlu et al, 2012; Sluzewska et al, 1995), no effect (Jazayeri et al, 2010; Maes et al, 1995a) or even increased level (Kubera et al, 2004; Munzer et al, 2013) (Table 2). This lack of consistency may be attributable to the heterogeneity of treatment responses in MDD (Kessler et al, 2016). In addition, the sex of the patient along with the type of drug may further obfuscate the relationship between antidepressant treatment and immune response. Men given serotonin-norepinephrine reuptake inhibitors (SNRIs) displayed increased levels of IL-6 and C-reactive protein (CRP) (Vogelzangs et al, 2012), whereas tricyclic antidepressants increased CRP in both sexes. Treatment with serotonin reuptake inhibitors (SSRIs) decreased IL-6 levels in men only. Neither SNRIs nor SSRIs significantly altered cytokine levels in women. Although studies investigating cytokine and immune cell abnormalities associated with stress vulnerability and resilience have been informative, further studies are necessary to address outstanding questions: is it possible to establish an immune molecular signature of resilience? Is the lack of heightened inflammation in resilient individuals maintained by active mechanisms? And lastly, would it be possible to predict a stress-related phenotype by stimulating circulating leukocytes and measuring cytokine release in humans?

\section{Stress and Central Immune Cells}

Microglia. Microglia constitute $10-15 \%$ of all brain cells and are the main active immune defense of the brain. These glial cells are tissue-resident macrophages that colonize the developing brain early during embryogenesis and become trapped after the blood-brain barrier forms (Ginhoux et al, 2010; Ransohoff and Brown, 2012). Microglia are highly dynamic and display stress-responsive morphological changes indicative of increased activity in stress-sensitive brain regions, notably the hippocampus, prefrontal cortex, and amygdala (Tynan et al, 2010; Wohleb et al, 2011). Reduction of microglial activity by administration of the inhibitor minocycline abolishes the pro-ramifying effect of stress (Hinwood et al, 2013) and rescues depression-like behaviors (Figure 1h) (Kreisel et al, 2014). Microglia dynamically survey their surrounding environment (Nimmerjahn et al, 2005), promote synaptic pruning (Stevens et al, 2007), and the recruitment of blood circulating monocytes to help manage tissue damage and local inflammation (Ajami et al, 2011; Yamasaki et al, 2014). Repeated stress may be sufficient to induce a deleterious inflammatory response potentially driven by microglia and/or infiltrating monocytes in the brain (Figure 1c). Indeed, dendritic cells along with monocytes and lymphocytes can enter the healthy brain in small numbers through the choroid plexus, brain lymphatic system, or circumventricular organs (Baruch and Schwartz, 2013; Louveau et al, 2015; Shechter et al, 2013). Elevated circulating inflammatory molecules and/or immune cells may trigger an opening of the gates separating the brain from the blood. In fact, Wohleb et al (2013) reported that repeated social stress not only induces an increase in circulating monocytes and brain macrophages but also the recruitment of peripheral myeloid cells within the perivascular space and parenchyma of stressrelated brain regions expressing high levels of IL- $1 \beta$ in mice. Interestingly, this migration is dependent upon the fractalkine receptor CX3CR1 and chemokine receptor 2 (CCR2) as mice deficient in these receptors did not develop anxiety-like behaviors and failed to recruit macrophages into the brain 
following RSD (Wohleb et al, 2013). Infiltration of monocytes into the mouse brain was also reported in the hippocampus following 5 consecutive days of electric footshock exposure (Brevet et al, 2010). All infiltrating monocytes developed microglia-like morphological ramifications and were positive for the microglia marker Iba-1 but negative for the astrocyte marker glial fibrillary acidic protein (GFAP) (Brevet et al, 2010). A follow-up study demonstrated that RSD leads to infiltration of bone marrow-derived monocytes in the paraventricular nucleus of the hypothalamus of mice subjected to chronic psychological stress (Ataka et al, 2013). In parallel, Wohleb et al (2011) report a concomitant increase in the expression of surface inflammatory markers such as TLR4 on resident microglia in socially defeated mice. Thus, chronic stress exposure affects not only microglial morphology but also microglial sensitivity. Taken together, these studies indicate that microglial function and peripheral cell recruitment play an active role in stress adaptation and may represent an attractive target to develop novel antidepressant treatments.

Astrocytes. Astrocytes, glial cells that engulf synapses and surround blood vessels, respond actively to inflammatory signals, inciting a growing interest in how astrocytic function and astrogliosis communicate with the immune system (Hodes et al, 2015a; Menard et al, 2016). Like microglia, astrocytes may be actively involved in stress-induced recruitment of peripheral monocytes through the expression of the chemokine ligand 2 (CCL2), also called monocyte chemoattractant protein-1 (MCP-1). CCL2 can activate CCR2 receptors on peripheral immune cells, promoting the invasion of inflammatory monocytes into the brain (Sica et al, 1990; Ransohoff and Tani, 1998). Astrocyte-mediated CCL2 release is sufficient to induce monocyte transmigration in a co-culture system meant to model aspects of the human blood-brain barrier (Weiss et al, 1999). Panenka et al (2001) reported that in cultured astrocytes, activation of ATP/purinergic receptor type 2X7 (P2X7R) increases CCL2 expression through mitogen-activated protein kinase activation, an effect that can be blocked by $\mathrm{P} 2 \mathrm{X} 7$ antagonists. Interestingly, CCL2 gene expression is upregulated in the dorsal anterior cingulate cortex of patients suffering from MDD who committed suicide (Torres-Platas et al, 2014). In line with these findings, Zheng et al (2016) recently reported that chemical dampening of peripheral Ly6 $\mathrm{C}^{\text {high }}$ monocyte recruitment and infiltration into the brain through inhibition of astrocyte activation and CCL2 release improves depression-like behaviors induced by either inflammation or chronic social defeat in mice. Further studies, supported by clinical findings, are necessary to elucidate the role astrocytes might play in the recruitment of peripheral immune cells and establishment of mood disorders.

Central cytokines and depression. Cytokines can directly cross the blood-brain barrier via saturable transport systems to act on astrocytes, neurons and microglia (Banks et al, 1995; Banks et al, 1994; Hodes et al, 2015a). Brain endothelial cells have the capacity to secrete cytokines (Verma et al, 2006) and thus may actively participate in the inflammatory response underlying chronic stress maladaptation. However, thus far most studies have investigated the role of activated microglia in inflammation and instigation of depression-like behaviors (Kreisel et al, 2014). Isolated microglia from rodents vulnerable to stress produce higher levels of the proinflammatory cytokines IL-1 $\beta$, IL- 6 , and TNF- $\alpha$ following LPS stimulation when compared with those of unstressed controls (Frank et al, 2007; Wohleb et al, 2011). Frank et al (2007) also showed that prior exposure to inescapable shock potentiates microglial pro-inflammatory responses 24 hours post stress in rat hippocampus. Interestingly, the effect of inescapable shock was comparable to the effect of ex vivo LPS stimulation, reinforcing the hypothesis that stress can prime microglial response to future psychological or physiological stressors. Conversely, treatment with SSRI and SNRI antidepressants suppresses microglial responses in murine microglial cell lines (Tynan et al, 2012), providing evidence that these drugs act in part by suppressing inflammation.

Acute and chronic stressors also induce activation of the NLRP3 inflammasome, which is constitutively expressed in macrophages and microglia (Figure 1d) (for review, refer to Iwata et al (2013)). NLRP3 is a cytosolic pattern recognition receptor that can be activated by either ATP or TLR4 binding, initiating pro-caspase-1 cleavage that subsequently cleaves pro-IL-1 $\beta$ to IL-1 $\beta$. Secretion of pro-inflammatory IL- $1 \beta$ by the activated microglia inflammasome is associated with increased depression-like behaviors in rodents, while NLRP3 null mutant mice exhibit resilience (Figure 1h) (Iwata et al, 2015). Administration of a P2X7R antagonist blocked IL-1 $\beta$ release and NLRP3 activation, promoting resilience to chronic unpredictable stress (Iwata et al, 2015). This study highlights a role for the ATP/P2X7R-IL-1 $\beta$ NLRP3 inflammasome cascade in the immune response to psychological stress. In line with these findings, IL-1 $\beta$ receptor inhibition via genetic or pharmacological interventions rescues anhedonia in rats exposed to chronic unpredictable stress (Koo and Duman, 2008) and prevents failure to escape in the LH paradigm (Maier and Watkins, 1995), suggesting a role for IL- $1 \beta$ and downstream signaling in stress vulnerability. Interestingly patients diagnosed with chronic inflammatory diseases such as diabetes, artherosclerosis, myocardial infarction and rheumatoid arthritis, who present with high rates of comorbid MDD, also tend to exhibit enhanced activation of the NLRP3 inflammasome complex (Mason et al, 2012).

As occurs in endothelial cells and microglia, the proinflammatory cytokines IL-1 $\beta$, IL- 6 , and TNF- $\alpha$ can activate receptors at the cell surface of astrocytes (Figure 1b) (Sofroniew, 2014). Astrocytes subsequently release cytokines and inflammatory mediators away from the perivascular region, affecting neighboring astrocytes, microglia, and neurons (for review, see Sofroniew, 2014). Transcriptome profiling of reactive human, rat and mouse astrocytes revealed broad changes following exposure to cytokines 
and/or inflammatory mediators including altered calcium signaling, reduced expression of G-protein effectors and growth factors, antigen presentation and regulation of astrocyte production of cytokines (Figure 1b) (Hamby et al, 2012; Meeuwsen et al, 2003; Pang et al, 2001; Sofroniew, 2014). Although each inflammatory molecule induces a specific molecular signature, astrocytes are generally exposed to multiple inflammatory markers and thus synergistic interactions are likely to occur as previously reported in immune cells (Korn et al, 2009). Stress-sensitive regions of the brain are highly interconnected (Russo et al, 2012), suggesting that an unresolved chronic neuroimmune response in even a restricted area may induce a chain reaction precipitating the development of stress-related disorders.

Other functions of activated microglia and astrocytes in stress-related synaptic plasticity. Synaptic plasticity is a highly dynamic process involving formation, strengthening, shrinking, and elimination of neuronal synapses (Hua and Smith, 2004; Katz and Shatz, 1996). During development, an activity-dependent elimination of immature synapses called synaptic pruning occurs, a process that likely involves microglia (Dalmau et al, 1998; Paolicelli et al, 2011; Tremblay et al, 2011). There is evidence for a similar but slower process of experience-dependent synapse remodeling and elimination in the healthy adult mouse brain, indicating that microglia may also influence synaptic structure in adulthood (Tremblay et al, 2010). Synapse development is impaired in mice deficient for the microglia-expressed chemokine receptor Cx3CR1 (Paolicelli et al, 2011). Cx3CR1 knockout mice are characterized by reduced microglial density and transient defects in synaptic plasticity and connectivity in the hippocampus (Paolicelli et al, 2011), a brain region essential for memory processes that is involved in various psychiatric disorders including MDD. At the behavioral level, mice lacking the Cx3CR1 receptor display hippocampal cognitive dysfunction and motor deficits that can be reversed by treatment with an IL-1 $\beta$ antagonist (Rogers et al, 2011). Surprisingly, Hellwig et al (2015) recently reported enhanced resilience to stress-induced depression-like behavior in Cx3CR1-deficient mice after 5 days of repetitive swim stress. Stress induced microglial hyper-ramification in wild-type mice as reported by other groups, but these morphological changes did not occur in Cx3CR1-deficient mice (Hellwig et al, 2015). As Cx3CR1 receptor binds to a chemokine fractalkine (Cx3CL1) expressed by neurons (Harrison et al, 1998), these findings potentially implicate microglia-neuron interactions in the development of stress-related disorders. However, it must be noted that Cx3CR1 is also expressed on peripheral monocytes and macrophages, and that selective knockout of Cx3CR1 in those cells promotes resilience to stress by preventing their recruitment to the mouse brain (Wohleb et al, 2013). Thus, future studies are needed to determine whether Cx3CR1 knockout specifically in microglia affects stress-related behaviors and neuronal function.
Microglia can affect neurotransmission and glutamate release through activation of purinergic signaling in astrocytes (Tremblay et al, 2011). ATP is an important mediator of brain intercellular communication and activation of astrocytic purinergic receptors has been shown to initiate TNF- $\alpha$ and prostaglandin-dependent glutamate release (Domercq et al, 2006). Increased glutamatergic synaptic transmission in stress-related brain regions has been associated with depression-like behaviors in mice (Christoffel et al, 2011b; Christoffel et al, 2015; Russo and Nestler, 2013), although it remains unclear whether this is due to an astrocyte-dependent mechanism. Astrocytes also maintain homeostasis and provide trophic support to neurons and other glial cells (Ridet et al, 1997). Moderate inflammation can lead to morphological hypertrophy of astrocytes while severe and chronic insults induce the release of pro-inflammatory cytokines and promote glial scar formation, triggering microglia-mediated inflammation (Sofroniew, 2009; Zhang et al, 2010). Hung et al (2016) recently reported that LPS induces growth-associated protein 43 (GAP-43) expression in rat brain astrocytes through

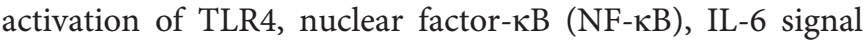
transducer and activator of transcription 3 (STAT3). Knockdown of GAP-43 or inhibition of downstream NF- $\mathrm{KB}$ signaling aggravated astrogliosis-induced microglial activation and expression of inflammatory cytokines, suggesting that this growth factor is important for inflammationinduced glial plasticity and attenuation of microglial activation (Hung et al, 2016). It would be interesting to evaluate GAP-43 expression in stress-susceptible $v s$ resilient mice in future studies as our laboratory has reported that NF- $\kappa \mathrm{B}$ signaling is implicated in altered neuronal morphology and depression-like behaviors in socially defeated mice (Christoffel et al, 2011a; Christoffel et al, 2012). Taken together, these findings highlight the diverse roles of a single signaling pathway in different cell types, promoting either vulnerability to stress or coping mechanisms associated with resilience.

\section{NEUROENDOCRINE MECHANISMS OF SUSCEPTIBILITY VS RESILIENCE AND INTERACTIONS WITH INFLAMMATORY PROCESSES}

We will now shift our focus to discuss neuroendocrine processes that are relevant to behavioral susceptibility and resilience as well as stress-induced inflammation. The autonomic nervous system (ANS), hypothalamo-pituitaryadrenal (HPA) axis and immune system are by no means mutually exclusive-they interact extensively to titrate hormonal and inflammatory stress response (Amsterdam et al, 2002). Immune cells express both adrenergic and GC receptors, making them sensitive to ANS and HPA signals. Furthermore, MDD and numerous inflammatory diseases are characterized by HPA axis dysfunction including reduced levels of HPA hormones as well as disrupted HPA-ANS cross 
talk and GC resistance (for review, refer to Straub et al, 2011). In this section, we will discuss co-regulation of stress response by HPA axis, ANS and immune processes, as well as the effect of gonadal sex hormones on susceptibility and resilience to stress.

\section{HPA Axis Stress Response and Circulating Glucocorticoids in Mood Disorders}

While the immune system appears to act directly on the brain during stressful situations, an appropriate response to stress exposure invariably involves the ANS and HPA axis (for comprehensive reviews, refer to McEwen et al, 2015; Ulrich-Lai and Herman, 2009). The ANS promotes an immediate physiological response by modulating heart rate and blood pressure through sympathetic and parasympathetic innervation. Meanwhile, slower activation of the HPA axis increases circulating GCs by promoting their synthesis and release from the adrenal cortex, resulting in widespread physiological, hormonal, and neurobiological effects. This circuit-designed to properly tune the stress response and maintain physiological homeostasis - may be altered in the chronically stressed brain, leading to the development of brain disorders (Figure 2a) (McEwen et al, 2015; Pfau and Russo, 2015; Ulrich-Lai and Herman, 2009). Indeed, GCs bind to steroid receptors expressed ubiquitously throughout the brain, altering gene expression and affecting synaptic plasticity, structural remodeling, and ultimately behavioral responses to stress and adaptive coping mechanisms of resilience (Figure 2e and f) (McEwen et al, 2015; Pfau and Russo, 2015; Russo et al, 2012). Moreover, GCs may produce a persistent sensitization of microglia-maintaining a proinflammatory state (Figure $2 \mathrm{~b}$ ) despite resolution of the stressful challenge-that primes neuroimmune responses to subsequent events (Frank et al, 2013). GC levels are elevated in the blood of about two-thirds of MDD patients, although an interesting subset of patients are characterized by lower GC levels and display less severe depressive symptoms according to a meta-analysis of 414 independent studies (Stetler and Miller, 2011). In this ambitious meta-analytic study, Stetler and Miller (2011) compared 671 effect sizes for parameters such as cortisol and HPA axis function-related hormones across 361 studies including over 18000 individuals. The authors observed that while depressed individuals exhibit increased cortisol and adrenocorticotropic hormone levels, they do not display elevated corticotropin-releasing hormone. Surprisingly, age, but not gender, affected HPA outcome. This finding is supported by studies including older hospitalized individuals that report greater cortisol differences between depressed and control subjects when compared with studies focusing on younger outpatient cohorts (Stetler and Miller, 2011). Cortisol differences may also be restricted to sub-populations of patients affected by specific forms of depression (Stetler and Miller, 2011). Altogether, these findings reinforce the need for future studies that account for the heterogeneity of depression, symptoms, and peripheral immune responses. Moreover,
HPA hyperactivity and resulting GC resistance may represent a promising link between MDD and diabetes or metabolic syndrome (Brown et al, 2004). In line with clinical findings, studies in animal models of depression suggest that the HPA axis is a critical mediator of stress response that can be shifted toward a resilient phenotype through a process termed stress inoculation. For example, rodents exposed to mild to moderate early-life stress in the form of postnatal handling, when compared with unstressed controls and rodents exposed to maternal separation (a more severe stressor) (Figure 2c), display reduced hormonal response to stress in adulthood (Plotsky and Meaney, 1993). This phenomenon has been attributed to the high levels of maternal care displayed by mothers of handled rodents compared with non-handled rodents. High levels of licking, grooming, and arched back nursing promote decreased repressive DNA methylation of the GC receptor gene promoter in handled pups, enhancing hippocampal expression of GC receptors and sensitivity to GC-negative feedback (Figure 2g) (Weaver et al, 2005). Interestingly, clinical studies have reported pro-resilience effects of high-dose GC administration in individuals vulnerable to PTSD, including combat-exposed veterans and patients hospitalized in intensive care units (Kearns et al, 2012; Schelling et al, 2006; Suris et al, 2010), suggesting that controlled intermittent exposure to stress mediators may promote resilience in humans. The mechanisms by which GC administration confers resilience in human populations are not yet fully understood but are thought to involve inhibition of traumatic memory consolidation (Kearns et al, 2012). Informative future experiments investigating the link between behavioral stress inoculation and the previously mentioned inoculation by exposure to activated immune cells would be valuable to the field. Important questions remain: does prior behavioral exposure to stress promote resilience through actions on adaptive immune cell compartments, and can these interactions be targeted therapeutically to treat mood disorders?

\section{HPA Axis Stress Response and Immune Cells}

GCs play a major role in attenuation of inflammatory response by inducing apoptosis in monocytes, macrophages, and $\mathrm{T}$ lymphocytes (Figure 2h) (Amsterdam et al, 2002) and suppressing NF- $\mathrm{KB}$ signaling (De Bosscher et al, 2003). They also exert a protective effect on resident cells surrounding sites of inflammation (Amsterdam et al, 2002). Chronic stress-induced GC resistance may dampen anti-inflammatory processes (Figure $2 \mathrm{~d}$ ) and induce prolonged production of pro-inflammatory mediators as proposed by Cohen et al (2012). In line with this hypothesis, Miller et al (2008) reported diminished expression of transcripts related to GCs coupled with heightened expression of transcripts associated with NF- $\mathrm{B}$ signaling in peripheral blood monocytes of familial caregivers of brain cancer patients. Similarly, adults who were raised in low-SES households exhibit higher Toll-like receptor-stimulated 
a Stress-susceptible/MDD

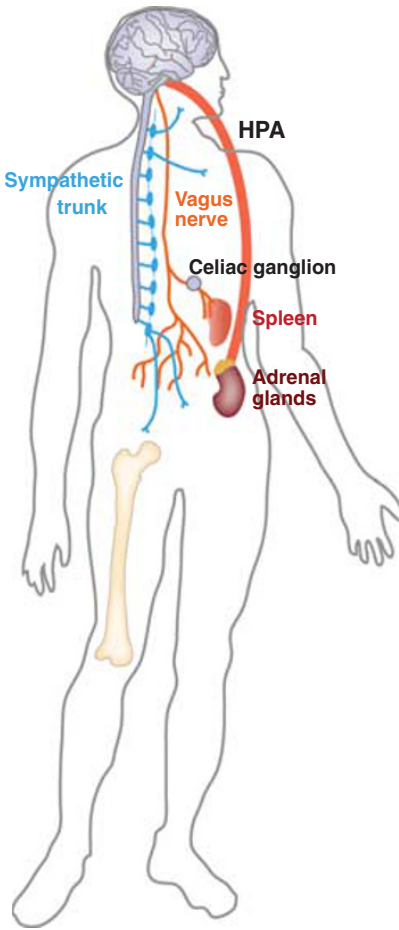

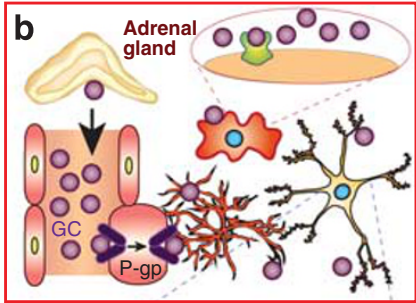
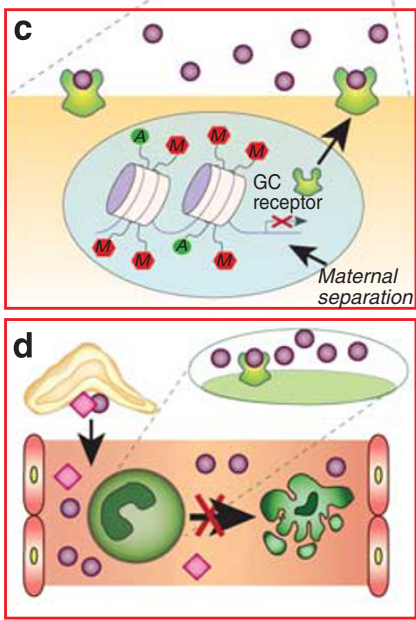

e Resilient/healthy

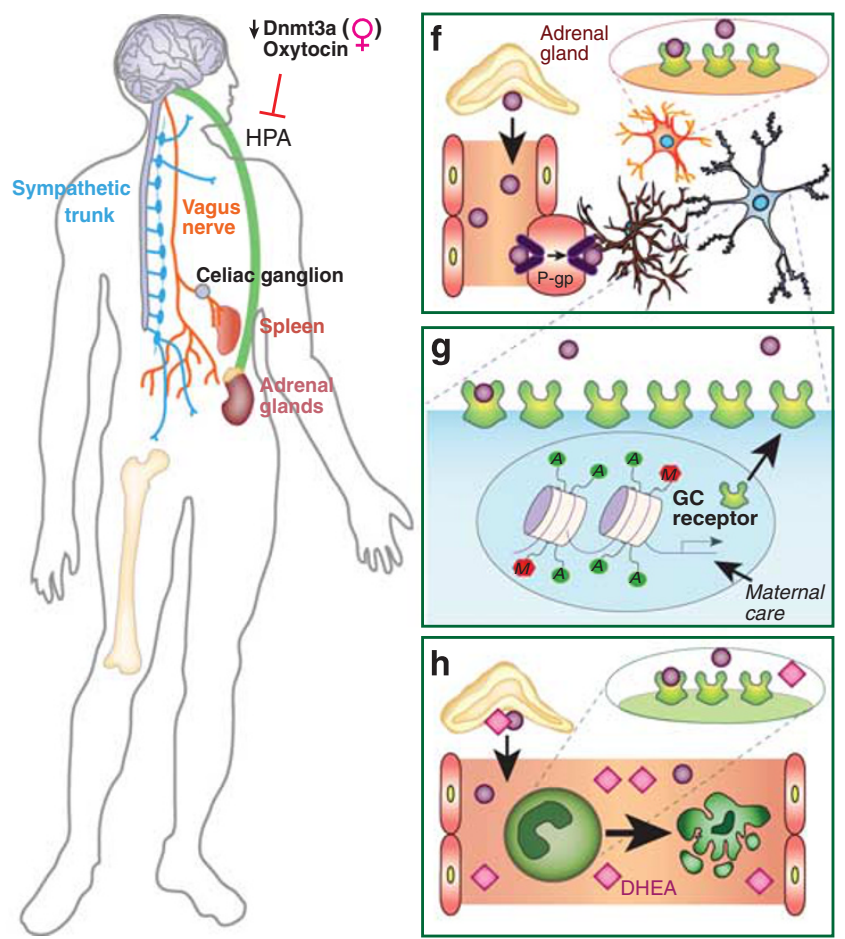

Figure 2. Neuroendocrine mechanisms of stress vulnerability and resilience. (a) Psychological stressors induce the activation of the hypothalamicpituitary-adrenal axis (HPA), a circuit designed to properly modulate stress response and maintain physiological homeostasis that may be hyperactive in stress-susceptible animals and MDD patients. (b) Circulating glucocorticoids (GCs), which are synthetized and released from the adrenal glands following HPA activation, can cross the blood-brain barrier through P-glycoprotein (P-gp) transporters of endothelial cells and bind to GC receptors on brain cells including microglia and neurons. Prolonged GC binding on microglial receptors may maintain these CNS-resident immune cells in a pro-inflammatory state leading to the establishment of depression-like behaviors. (c) Severe early-life stressors, such as maternal separation, can affect GC receptor epigenetic regulation and promote repressive methylation reducing its expression at the cell surface and inducing GC resistance. (d) GCs play a major role in attenuation of inflammatory response by inducing apoptosis in immune cells, a process that might be involved in stress vulnerability. (e) Clinical studies reported sex differences in HPA response to stressors. Downregulation of DNA methyltransferase 3a (Dnmt3a) activity may promote resilience in a genderspecific manner by modulating gene expression in stress-related brain regions and possibly HPA axis response. The hormone oxytocin, which plays a role in social bonding, parturition and lactation, can reduce HPA axis activation inducing antidepressant effect. (f) Low circulating GC level and high expression of GC receptor in brain cells are associated with proper HPA axis response and a resilient phenotype. (g) Life experience such as high level of maternal care during childhood can positively alter epigenetic regulation of GC receptor gene, leading to enhanced GC receptor expression in brain and immune cells and reduced stress vulnerability. (h) Exogenous GC replacement with dehydroepiandrosterone (DHEA), a precursor for the synthesis of anabolic steroids released from the adrenal cortex with cortisol in response to stress, may blunt stress-induced HPA axis activation, promoting resilience.

production of IL-6 and transcriptional activation of NF- $\mathrm{KB}$ signaling in peripheral blood mononuclear cells (Chen et al, 2011). Reminiscent of rodent studies of maternal behavior by Meaney's group, subjects who experienced high maternal warmth in early life were protected from low SES-induced inflammation compared with those living in similar environments but with lower maternal warmth (Chen et al, 2011). A study conducted in non-human primates provided additional evidence of adverse early-life social conditions altering leukocyte transcriptional profiles. Early-life stress promoted enhanced expression of genes involved in inflammation, cytokine signaling, and T-lymphocyte activation, but suppressed genes associated with innate antimicrobial and antiviral responses (Cole et al, 2012). As mentioned earlier, pro-inflammatory transcriptional responses have also been reported in leukocytes of socially defeated mice (Powell et al, 2013). Furthermore, following SDR, splenic leukocytes from stressed mice are more sensitive to LPS stimulation and release higher levels of pro-inflammatory cytokines IL-6 and TNF $\alpha$ compared with unstressed controls (Avitsur et al, 2003). Mouse splenic macrophages and monocytes are less sensitive to the inhibitory effects of GCs after 6 days of psychosocial stress (Avitsur et al, 2005; Stark et al, 2001) indicating a dysregulation of the negative feedback mechanisms suppressing inflammatory signaling. In patients under chronic interferon- $\alpha$ treatment to control hepatitis $\mathrm{C}$ virus, interferon- $\alpha$-induced inflammation was associated with reduced GCnegative feedback sensitivity and depressive symptoms (Felger et al, 2015a). Overall, these findings highlight an important role for immune-ANS-HPA interactions in maladaptive stress responses and shed light on the comorbidity of inflammatory diseases with MDD, as immune cell GC resistance has been raised as a major barrier to treating inflammatory diseases (Barnes and Adcock, 2009). 


\section{Sex Differences in HPA-Axis-Mediated Stress Response}

MDD and mood disorders are more prevalent in women (Kessler et al, 1993), suggesting that sex differences may play a role in the pathogenesis of these diseases. In fact, sexual dimorphism in the stress response has been observed in various animal models of depression (for review, refer to Pfau and Russo, 2015). Overall, adult female rodents exhibit greater cognitive resilience to chronic stress, while their male counterparts display enhanced emotional resilience. In line with these behavioral observations, chronic restraint stress modifies hippocampal CA3 neuronal morphology, which is closely associated with memory formation, in male but not female rats (Galea et al, 1997). GC receptor density is reduced in male rat hippocampus after 21 days of restraint stress (Kitraki et al, 2004). However, receptor density is enhanced in females, providing a potential explanation for gender-specific spatial memory performance discrepancies in animal models of depression (Kitraki et al, 2004). Clinical findings paint a more complicated picture, suggesting gender-specific HPA axis dysfunction in human patients and supporting hypotheses that the experience and symptoms of depression are different in men and women (Martin et al, 2013). Cortisol level is significantly higher in men meeting criteria for MDD compared with healthy controls, while no difference is observed in depressed women, suggesting that HPA axis hyperactivity may be more characteristic of male depression (Sanches et al, 2013). Furthermore, Kirschbaum et al (1995) suggest that a subpopulation of healthy men may be unable to adapt their adrenocortical stress response to repeated psychological stress leading to HPA axis hyperactivity and a higher risk of developing mood disorders. Shedding additional light on these findings, Suarez et al (2015) evaluated corticosterone (CORT) to CRP ratio, a measure that is thought to indicate the efficiency of homeostatic HPA-immune regulatory mechanisms and predict vulnerability to MDD. CRP is synthetized by hepatocytes in response to IL- 6 release and becomes elevated shortly after the onset of inflammation, while CORT is subsequently released upon activation of the HPA axis. Low CORT/CRP ratios indicate a blunted HPA axis-related response to elevation of inflammatory signals. CORT/CRP ratio was associated with severity of depressive symptoms in a gender-specific manner (Suarez et al, 2015). Depressed women were characterized by lower CORT/CRP ratios, suggesting insufficient release of CORT despite heightened inflammatory state. In contrast, anxiety was correlated with higher CORT/CRP ratio in men, indicating a hyperactive response of the HPA axis (Suarez et al, 2015). Before this study, Miller et al (2005) reported lower CORT release in response to acute stress-induced inflammation in depressed women when compared with healthy controls. In this study, subjects were exposed to a mock job interview and blood was drawn to assess secretion and regulation of inflammatory molecules. Stress was associated with anxious behaviors as well as mobilization of monocytes and neutrophils and enhanced stimulated release of IL- 6 and TNF- $\alpha$ by leukocytes in vitro (Miller et al, 2005). Interestingly, before the stressful experience, depressed women displayed greater sensitivity to the anti-inflammatory properties of GC in comparison with healthy controls. However, after the stressor, GCs sensitivity decreased only among depressed women (it increased in controls), indicating impairment in HPA axis regulation of stress-related inflammation. This study focused exclusively on female subjects, but additional studies on HPA axis sensitivity in depressed men (as opposed to healthy controls exposed to acute stress) would be informative.

Animal studies suggest that initiation of sex differences in vulnerability to stress may occur even before birth. Indeed, in mice, male offspring of mothers that have been exposed to chronic unpredictable stress during early pregnancy develop depression-like behaviors while female offspring do not (Mueller and Bale, 2008). These gender-specific maladaptive behavioral responses were associated with exacerbated HPA axis response, long-term alterations in amygdala corticotropin-releasing factor (CRF) expression and decreased hippocampal GC receptor expression driven by enhanced repressive methylation at the GC receptor promoter. Placental expression profiles also suggest a role for DNA methyltransferase 1 (Dnmt1), a methylation maintenance enzyme, in the establishment of adult phenotypes (Mueller and Bale, 2008). In line with these findings, our laboratory recently reported DNA methyltransferase 3a (Dnmt3a) -dependent sex differences in adult mouse nucleus accumbens (NAc) transcriptome profiles following exposure to subchronic variable stress (SCVS) (Hodes et al, 2015b). This 6-day stress paradigm is sufficient to induce depressionlike behaviors in female, but not male, mice, allowing us to explore mechanisms underlying sex differences in stress response. NAc RNA-sequencing revealed gender-specific stress regulation of gene expression (Hodes et al, 2015b). Dnmt3a was among the genes upregulated only in females and local overexpression of Dnmt3a in the NAc rendered male mice more susceptible to SCVS. Conversely, knocking down Dnmt3a in NAc rendered females more resilient. Moreover, the female transcriptome shifted toward a more male-like pattern, indicating a role for this gene in stressrelated sex differences (Hodes et al, 2015b). Interestingly, one of the most enriched biological pathways regulated by Dnmt3a was the CRF pathway, suggesting a role for HPA axis regulation in sex differences in stress vulnerability (Figure 2e). These studies, as well as additional preclinical evidence (for comprehensive review, please refer to Hodes (2013)), suggest an important role for experience-dependent epigenetic modifications in sexual dimorphism of stress sensitivity. In contrast to clinical studies, which largely employ blood samples, most studies in animal models focus on sex differences in HPA axis response in CNS tissues. Further investigation of sex differences in neuroendocrineimmune regulation of stress vulnerability in immune cells would provide valuable insight into depression etiology and treatment. 


\section{Sex Differences in Microglial Activation}

Numerous recent studies outline an interesting link between immune cells, hormonal processes, and development, suggesting that microglial activation may play a role in brain sex differences and masculinization (for review, refer to Lenz and McCarthy (2015)). Indeed, inhibition of these immune cells during the critical period for sexual differentiation in rodents can prevent morphological changes generally associated with the male brain in the preoptic area (POA), a highly sexually dimorphic nucleus involved in male sexual behavior (Lenz et al, 2013). At the morphological level, the POA is five- to seven-fold larger in males (Gorski et al, 1978) and its neurons exhibit two to three times more dendritic spines as well as more complex astrocytic processes (Amateau and McCarthy, 2002, 2004). Furthermore, neonatal male brains contain twice as many microglia cells as do female brains (Lenz and McCarthy, 2015). Although the mechanisms of sex differences in microglia-dependent masculinization are not well established, microglia express prostaglandin receptors that may be actively involved in gender-specificity of POA-mediated behaviors through direct interactions with neurons (Lenz et al, 2013). For example, a single exposure to prostaglandins is sufficient to not only shift neuronal morphology toward a masculine phenotype but also alter sexual behavior in adulthood (Wright and McCarthy, 2009). Conversely, inhibition of prostaglandins synthesis with a cyclooxygenase (COX) inhibitor downregulates dendritic spine density and impairs sexual behaviors in males (Amateau and McCarthy, 2004). These intriguing results provide evidence for distinct neuroimmune interactions during sexual differentiation of the brain; however, it is not clear whether similar mechanisms are involved in sex differences in stress-induced plasticity during adulthood. A few recent studies have hinted that this might be the case.

Around the beginning of puberty and into early adulthood, female rats develop more microglia than do males in select brain areas including the amygdala, parietal cortex, and hippocampus (Schwartz et al, 2012; Hanamsagar and Bilbo, 2015). During adulthood, females have a greater ratio of primed microglia to ramified microglia compared with males. There are also prominent sex differences in the effects of restraint stress on microglial morphology in the medial prefrontal cortex of adult rats. Exposure to either acute or chronic restraint stress reduced the proportion of primed microglia in females but not males (Bollinger et al, 2016). This study raises the interesting possibility that females are normally in a more activated central immune state than males, and that stress acts to suppress these responses in females. However, additional research is needed to determine the functional contribution of these basal sex differences in stress susceptibility and resilience. More research is also required to elucidate whether sex-specific stress effects on microglial activation and morphology are ubiquitous through the brain or occur only in particular regions related to emotionality.

\section{FUTURE DIRECTIONS-ANTI-INFLAMMATORY AND HORMONAL THERAPEUTICS TO TREAT MOOD DISORDERS}

Recent ongoing clinical studies are translating basic research findings regarding the role of the immune and neuroendocrine systems into clinical practice. Below, we highlight clinical findings most relevant to immune and hormonal processes.

\section{Anti-inflammatory Therapeutics}

Considering the mounting evidence supporting a role for the immune system in development of mood disorders and possibly resistance to current antidepressant treatments, clinical studies have evaluated potential benefits of anti-inflammatory agents in depressed patients (Box 1). A meta-analysis of randomized clinical trials including 10 for non-steroidal anti-inflammatory drugs (NSAIDs) and four for cytokine inhibitors provides proof-of-concept for using anti-inflammatory treatments to reduce depressive symptoms (Kohler et al, 2014). The selective COX-2 inhibitor celecoxib seems to be particularly effective in producing antidepressant effect, as measured by treatment response and remission. Moreover, no evidence of gastrointestinal or cardiovascular side effects was observed after chronic treatment when compared with placebo (Kohler et al, 2014). However, non-selective COX inhibition does not seem to be as efficient (Eyre et al, 2015). There have also been some reported benefits of NSAID therapy on depressive symptoms in patients suffering from osteoarthritis (Iyengar et al, 2013), raising the possibility of monotherapy to treat comorbid inflammatory diseases and MDD. However, it should be noted that overall the evidence supporting antidepressant effects of these more traditional nonselective anti-inflammatory medications is not very strong. In addition, some anti-inflammatory drugs could potentially interfere with the bioavailability of widely prescribed antidepressants such as SSRIs, raising concerns for clinicians and highlighting the need to carefully consider side effect profiles when combining NSAIDs with traditional antidepressants (Warner-Schmidt et al, 2011).

Treatment of depressed patients with humanized antibodies that more selectively target individual proinflammatory cytokines (Figure 1f) has also been evaluated in recent clinical trials. A double-blind, placebo-controlled randomized clinical trial revealed an improvement of depressive symptoms in patients treated with infliximab (Raison et al, 2013), a chimeric monoclonal antibody against $\mathrm{TNF} \alpha$ generally used to treat autoimmune diseases (Willrich et al, 2015). However, efficacy was limited to patients presenting a high baseline level of inflammation as assessed by CRP concentration at the beginning of the trial (Raison et al, 2013). The therapeutic potential of IL-6 antagonism to treat bipolar and unipolar disorder has been proposed following reports of increased IL-6 level during manic and depressive episodes (Brietzke et al, 2011). The use of 
BOX 1 Past and Ongoing Clinical Trials for MDD with Anti-inflammatory Drugs and Hormonal Therapeutics

Celecoxib is a COX-2 selective non-steroidal anti-inflammatory drug (NSAID). Two clinical trials are currently recruiting participants. One will attempt to enhance and augment the antidepressant efficacy of escitalopram by combining it with celecoxib in poorly responding bipolar depressed patients (NCTO I479829). The other will evaluate antidepressant properties of 8-week celecoxib treatment in depressed patients resistant to minocycline beneficial effects by measuring depressive scores with the Hamilton Depression Rating Scale (NCT02362529). Infliximab is a chimeric monoclonal antibody against TNF- $\alpha$ generally used to treat autoimmune diseases. A completed 12 -week clinical trial including three infusions of either infliximab or placebo at weeks 0,2 and 6 did not reveal generalized efficacy in treatment-resistant depression but note an overall improvement of depressive symptoms in patients suffering from MDD with high baseline inflammatory markers (NCT00463580) (Raison et al, 2013). Another trial not yet open for participant recruitment will soon evaluate the efficacy of I2-week infliximab treatment on bipolar I/II depression in individuals exhibiting signs of high inflammation (NCT02363738).

Tocilizumab is a humanized monoclonal antibody against the IL-6 receptor used as an immunosuppressive drug in the treatment of rheumatoid arthritis and systemic juvenile idiopathic arthritis. A clinical trial, not yet open for participant recruitment; will examine antidepressant effects of 8-week tocilizumab treatment in patients suffering from treatment-refractory MDD using the Hamilton Depression Rating Scale and remission rate (NCT02660528).

Sirukumab is a humanized monoclonal antibody against the pro-inflammatory cytokine IL-6, used to treat rheumatoid arthritis, currently in phase 2 clinical trials for the treatment of depression. This 12-week study consists of three subcutaneous injections at days I, 28 and 56 in participants diagnosed with MDD and resistant to current standard oral antidepressant treatment but also characterized by high C-reactive protein sensitivity. Efficacy of sirukumab treatment on depressive symptoms will be compared with adjunctive placebo at the 12-week end point (NCT02473289).

Ketamine is an anesthetic uses for sedation and chronic pain relief displaying robust antidepressant effects. A search on www.clinicaltrials.gov revealed over 100 completed or recruiting trials evaluating the antidepressant effects of ketamine in MDD or treatment-resistant depression, bipolar depression, suicidal ideation, etc. However, only two trials currently recruiting participants propose to investigate if ketamine treatment affects MDD-related peripheral inflammation. The first one will evaluate the effects of repeated infusions of ketamine on severity of depressive symptoms in treatment-resistant depressed patients and inflammatory mediator's expression as a secondary outcome measure (NCTO1945047). The second one will determine the efficacy of 24 hours intravenous low-dose of ketamine to improve depressive symptoms and reduce circulating IL-I and TNF $\alpha$ levels (NCT026107/2).

DHEA is an endogenous steroid hormone. To our knowledge no clinical trial has directly assessed its efficacy on MDD-related inflammation yet despite reported beneficial effects on depressive symptoms.

Oxytocin is an endogenous hormone involved in social bonding, reproduction and lactation. An ongoing trial will evaluate the efficacy of a single-dose administration of oxytocin on postpartum depressive symptoms and assess its effect on brain activity and connectivity in empathy-related brain regions (NCT02/9|423). Another trial will evaluate the efficacy of intranasal oxytocin administration during the first postpartum days in mothers at risk to develop postpartum depression (NCT02505984). Clinical trials evaluating oxytocin efficacy to treat depressive symptoms are not restricted to postpartum depression. One trial currently recruiting participants will compare the efficacy of intranasal oxytocin treatment vs placebo, both combined to interpersonal psychotherapy, in the treatment of major depressive disorder (NCT024057I5). However according to the information available none of these trials are measuring outcomes related to peripheral inflammation.

tocilizumab, a humanized antibody against IL-6 receptor, or sirukumab, a humanized antibody against IL-6 have been proposed as novel antidepressant therapeutics (Traki et al, 2014; Hsu et al, 2015). Two ongoing clinical trials will examine the antidepressant effects of tocilizumab and sirukumab among patients with treatment-refractory major depression (www.clinicaltrials.gov).

If inflammatory processes are involved in MDD pathogenesis, one might assume that treatment with antidepressants should at least partly reduce overall inflammatory load. Recent findings suggest that ketamine, a novel antidepressant producing rapid action and long-term positive effects in treatment-resistant depressed patients (Murrough et al, 2013a; Murrough et al, 2013b), can decrease levels of the pro-inflammatory cytokines IL- $1 \beta$, IL- 6 , and TNF $\alpha$, possibly through inhibition of TLR4 (for review, refer to De Kock et al (2013)). Conversely, evidence assessing effects of traditional antidepressants on inflammation is mixed with studies reporting a reduction (Sluzewska et al, 1995), no effect (Jazayeri et al, 2010; Maes et al, 1995a), or even an increase (Kubera et al, 2004) in circulating IL-6 levels. These discrepancies could be related to methodological heterogeneity across variables including age, gender, depressive measures, severity of depressive symptoms, and type and duration of antidepressant treatment; as well as study design and duration, or the fact that increased inflammation is not ubiquitously treated with standard antidepressant treatments.

\section{Hormonal Therapeutics}

Clinical studies suggest a promising role for exogenous GC replacement in blunting stress-induced HPA axis activation and promoting resilience (Box 1). A study conducted in patients suffering from PTSD revealed that dehydroepiandrosterone (DHEA), a precursor for the synthesis of anabolic steroids released from the adrenal cortex with cortisol in response to stress, possesses antiglucocorticoid properties (Rasmusson et al, 2003; Russo et al, 2012). DHEA level increases rapidly in blood under acute stress, and higher DHEA-to-cortisol ratio promotes resilience (Figure $2 \mathrm{~h}$ ) (Rasmusson et al, 2003). In contrast, lower DHEA-tocortisol ratio correlates with greater severity of PTSD symptoms (Figure 2d) (Yehuda et al, 2006). A metaanalysis of clinical studies reported lower DHEA sulfate derivative (DHEAS) in individuals diagnosed with depression. However, ethnicity-stratified analysis indicated that lower levels of DHEAS were not observed in Caucasian and Asian depressed patients (Hu et al, 2015). These discrepancies could explain the lack of benefit of DHEA supplementation on subjective stress in an initial randomized trial of men undergoing military survival training (Taylor et al, 2012). Alternatively, DHEA level decreases with normal aging and this reduction may be linked to age-related decline in immune function and increased prevalence of mood disorders. In mice, altered regulation of IL-6 production can be prevented or reversed with DHEAS supplements (Daynes et al, 1993). These observations were later corroborated in human: serum DHEA/DHEAS decreases while IL-6 level increases with age in both men and women, leading to a significant inverse correlation between DHEA/DHEAS and IL-6 (but not TNF $\alpha$ ) levels in peripheral blood mononuclear cells (Straub et al, 1998). MDD is highly prevalent in older adults and may be a preventable risk factor for dementia (for review, refer to Wang and Blazer (2015b)). Considering the rapid growth of aged human populations, further studies are necessary to better understand and therapeutically address age-related neuroimmune and 
neurobiological changes that may be associated with MDD in the elderly.

Another target that could promote resilience through direct actions on immune function is the neuropeptide oxytocin. Although conventionally viewed as a hormone responsible for parturition and lactation, oxytocin is also associated with prosocial behaviors such as social bonding, altruism, empathy, and positive communication (for reviews refer to McQuaid et al (2014) and Wang et al (2015a)). It acts as a neuromodulator in multiple brain regions involved in stress-related disorders and thus may contribute to the development of MDD. In fact, administration of oxytocin has strong antidepressant effects in rodents across multiple behavioral domains (Arletti and Bertolini, 1987; Grippo et al, 2009). Oxytocin reduces HPA axis activation (Figure 2e) and pro-inflammatory cytokine release in response to LPS stimulation in healthy men (Clodi et al, 2008). Norman et al (2010) showed that oxytocin administration attenuated cortical IL-1 $\beta$ expression and depression-like behaviors following spared nerve injury in socially isolated mice. Conversely, treatment of pair-housed animals with an oxytocin receptor antagonist induced a depressive phenotype and increases IL- $1 \beta$ level in the frontal cortex (Norman et al, 2010). Clinical studies have reported that circulating oxytocin is reduced in patients suffering from MDD (Frasch et al, 1995) and negatively correlates with depressive symptoms (Scantamburlo et al, 2007). However, no difference was measured in cerebrospinal fluid (Sasayama et al, 2012) and other studies reported contradictory findings (Parker et al, 2010) that may be related to gender-specific effects (Ozsoy et al, 2009; Yuen et al, 2014). These discrepancies may also be related to variability of subjects' depressive symptoms, antidepressant treatments and past experiences. Indeed, early-life challenges such as childhood abuse were associated with lower plasma oxytocin levels in both men (Opacka-Juffry and Mohiyeddini, 2012) and women (Heim et al, 2009), suggesting an inherent oxytocin-dependent vulnerability to stressors in adult life. Despite the excitement surrounding oxytocin therapeutics, far more work is needed to fully understand the role of oxytocin in proper immune function and depression.

\section{CONCLUSIONS}

Taken together, findings from both clinical studies and rodent models of depression support an active role for the neuroendocrine and immune systems in stress response and vulnerability to mood disorders. Identification and characterization of dysregulated immune and hormonal processes observed in patients suffering from MDD that have been reverse translated into rodent models to show causation has helped us to better understand the neuroimmune mechanisms of depression. Reciprocally, basic research findings have been applied to clinical research and therapeutic trials, producing encouraging results. Nevertheless, further research is required to determine key cellular and molecular mechanisms affecting stress-related immune and neuroendocrine responses and stress-induced plasticity in central and peripheral systems. For instance, future studies should investigate innate and adaptive immune responses in stress-susceptible $v s$ resilient animals, and evaluate whether manipulation of inflammatory mediators is an effective means to promote resilience to stress. Although many clinical studies have been conducted in depressed patients, only a handful investigated mechanisms of resilience. Intriguing future clinical studies could recruit highly resilient individuals for comparison with depressed patients and healthy controls. Increasing insight into the biology of resilience may help us to elucidate novel targets for more broadly effective treatment of mood disorders.

\section{FUNDING AND DISCLOSURE}

The authors declare no conflict of interest.

\section{ACKNOWLEDGMENTS}

This research was supported by grants from the National Institutes of Health R01 MH090264 (Role of thalamic vs cortical inputs to nucleus accumbens in stress-related disorders), R01 MH104559 (Peripheral IL-6 from leukocytes controls susceptibility to social defeat stress) to SJR and P50 AT008661-01, titled "Dietary Botanicals in the Preservation of Cognitive and Psychological Resilience" from the National Center for Complementary and Integrative Health $(\mathrm{NCCIH})$ and the Office of Dietary Supplements (ODS).

\section{REFERENCES}

Ainiala H, Loukkola J, Peltola J, Korpela M, Hietaharju A (2001). The prevalence of neuropsychiatric syndromes in systemic lupus erythematosus. Neurology 57: 496-500.

Ajami B, Bennett JL, Krieger C, McNagny KM, Rossi FM (2011). Infiltrating monocytes trigger EAE progression, but do not contribute to the resident microglia pool. Nat Neurosci 14: 1142-1149.

Ali S, Stone MA, Peters JL, Davies MJ, Khunti K (2006). The prevalence of co-morbid depression in adults with type 2 diabetes: a systematic review and meta-analysis. Diabet Med 23: 1165-1173.

Amateau SK, McCarthy MM (2002). Sexual differentiation of astrocyte morphology in the developing rat preoptic area. J Neuroendocrinol 14: 904-910.

Amateau SK, McCarthy MM (2004). Induction of PGE2 by estradiol mediates developmental masculinization of sex behavior. Nat Neurosci 7: 643-650.

Amsterdam A, Tajima K, Sasson R (2002). Cell-specific regulation of apoptosis by glucocorticoids: implication to their anti-inflammatory action. Biochem Pharmacol 64: 843-850.

Anderson RJ, Freedland KE, Clouse RE, Lustman PJ (2001). The prevalence of comorbid depression in adults with diabetes: a meta-analysis. Diabetes Care 24 1069-1078.

Arletti R, Bertolini A (1987). Oxytocin acts as an antidepressant in two animal models of depression. Life Sci 41: 1725-1730

Ataka K, Asakawa A, Nagaishi K, Kaimoto K, Sawada A, Hayakawa Y et al (2013). Bone marrow-derived microglia infiltrate into the paraventricular nucleus of chronic psychological stress-loaded mice. PLoS One 8: e81744.

Avitsur R, Kavelaars A, Heijnen C, Sheridan JF (2005). Social stress and the regulation of tumor necrosis factor-alpha secretion. Brain Behav Immun 19: 311-317.

Avitsur R, Padgett DA, Dhabhar FS, Stark JL, Kramer KA, Engler H et al (2003). Expression of glucocorticoid resistance following social stress requires a second signal. J Leukoc Biol 74: 507-513.

Avitsur R, Stark JL, Sheridan JF (2001). Social stress induces glucocorticoid resistance in subordinate animals. Horm Behav 39: 247-257. 
Baker DG, Ekhator NN, Kasckow JW, Hill KK, Zoumakis E, Dashevsky BA et al (2001). Plasma and cerebrospinal fluid interleukin-6 concentrations in posttraumatic stress disorder. Neuroimmunomodulation 9: 209-217.

Banks WA, Kastin AJ, Broadwell RD (1995). Passage of cytokines across the bloodbrain barrier. Neuroimmunomodulation 2: 241-248.

Banks WA, Kastin AJ, Gutierrez EG (1994). Penetration of interleukin-6 across the murine blood-brain barrier. Neurosci Lett 179: 53-56.

Barnes PJ, Adcock IM (2009). Glucocorticoid resistance in inflammatory diseases. Lancet 373: 1905-1917.

Baruch K, Schwartz M (2013). CNS-specific T cells shape brain function via the choroid plexus. Brain Behav Immun 34: 11-16.

Basterzi AD, Aydemir C, Kisa C, Aksaray S, Tuzer V, Yazici Ket al (2005). IL-6 levels decrease with SSRI treatment in patients with major depression. Hum Psychopharmacol 20: 473-476.

Berk M, Wadee AA, Kuschke RH, O'Neill-Kerr A (1997). Acute phase proteins in major depression. J Psychosom Res 43: 529-534.

Berton O, McClung CA, Dileone RJ, Krishnan V, Renthal W, Russo SJ et al (2006). Essential role of BDNF in the mesolimbic dopamine pathway in social defeat stress. Science 311: 864-868.

Black C, Miller BJ (2015). Meta-analysis of cytokines and chemokines in suicidality: distinguishing suicidal versus nonsuicidal patients. Biol Psychiatry 78: 28-37.

Bollinger JL, Bergeon Burns CM, Wellman CL (2016). Differential effects of stress on microglial cell activation in male and female medial prefrontal cortex. Brain Behav Immun 52: 88-97.

Bomasang-Layno E, Fadlon I, Murray AN, Himelhoch S (2015). Antidepressive treatments for Parkinson's disease: a systematic review and meta-analysis. Parkinsonism Relat Disord 21: 833-842.

Brachman RA, Lehmann ML, Maric D, Herkenham M (2015). Lymphocytes from chronically stressed mice confer antidepressant-like effects to naive mice. J Neurosci 35: 1530-1538.

Brevet M, Kojima H, Asakawa A, Atsuchi K, Ushikai M, Ataka Ket al (2010). Chronic foot-shock stress potentiates the influx of bone marrow-derived microglia into hippocampus. J Neurosci Res 88: 1890-1897.

Brietzke E, Scheinberg M, Lafer B (2011). Therapeutic potential of interleukin-6 antagonism in bipolar disorder. Med Hypotheses 76: 21-23.

Brown ES, Varghese FP, McEwen BS (2004). Association of depression with medical illness: does cortisol play a role? Biol Psychiatry 55: 1-9.

Charney DS (2004). Psychobiological mechanisms of resilience and vulnerability: implications for successful adaptation to extreme stress. Am J Psychiatry 161: 195-216.

Chen E, Miller GE, Kobor MS, Cole SW (2011). Maternal warmth buffers the effects of low early-life socioeconomic status on pro-inflammatory signaling in adulthood. Mol Psychiatry 16: 729-737.

Chourbaji S, Zacher C, Sanchis-Segura C, Dormann C, Vollmayr B, Gass P (2005). Learned helplessness: validity and reliability of depressive-like states in mice. Brain Res Brain Res Protoc 16: 70-78.

Christoffel DJ, Golden SA, Dumitriu D, Robison AJ, Janssen WG, Ahn HF et al (2011a). IkappaB kinase regulates social defeat stress-induced synaptic and behavioral plasticity. J Neurosci 31: 314-321.

Christoffel DJ, Golden SA, Heshmati M, Graham A, Birnbaum S, Neve RL et al (2012). Effects of inhibitor of kappaB kinase activity in the nucleus accumbens on emotional behavior. Neuropsychopharmacology 37: 2615-2623.

Christoffel DJ, Golden SA, Russo SJ (2011b). Structural and synaptic plasticity in stress-related disorders. Rev Neurosci 22: 535-549.

Christoffel DJ, Golden SA, Walsh JJ, Guise KG, Heshmati M, Friedman AK et al (2015). Excitatory transmission at thalamo-striatal synapses mediates susceptibility to social stress. Nat Neurosci 18: 962-964.

Clodi M, Vila G, Geyeregger R, Riedl M, Stulnig TM, Struck J et al (2008). Oxytocin alleviates the neuroendocrine and cytokine response to bacterial endotoxin in healthy men. Am J Physiol Endocrinol Metab 295: E686-E691.

Cohen H, Ziv Y, Cardon M, Kaplan Z, Matar MA, Gidron Y et al (2006). Maladaptation to mental stress mitigated by the adaptive immune system via depletion of naturally occurring regulatory CD4+CD25+ cells. J Neurobiol 66: 552-563. This study suggests a role for adaptive immunity mediated by $\mathrm{T}$ cells in the development of post-traumatic stress disorder.

Cohen S, Janicki-Deverts D, Doyle WJ, Miller GE, Frank E, Rabin BS et al (2012). Chronic stress, glucocorticoid receptor resistance, inflammation, and disease risk. Proc Natl Acad Sci USA 109: 5995-5999.

Cole SW, Conti G, Arevalo JM, Ruggiero AM, Heckman JJ, Suomi SJ (2012). Transcriptional modulation of the developing immune system by early life social adversity. Proc Natl Acad Sci USA 109: 20578-20583.

Conversano C, Carmassi C, Carlini M, Casu G, Gremigni P, Dell'Osso L (2015). Interferon alpha therapy in patients with chronic hepatitis c infection: quality of life and depression. Hematol Rep 7: 5632.
Cruess DG, Evans DL, Repetto MJ, Gettes D, Douglas SD, Petitto JM (2003). Prevalence, diagnosis, and pharmacological treatment of mood disorders in HIV disease. Biol Psychiatry 54: 307-316.

Dalmau I, Finsen B, Zimmer J, Gonzalez B, Castellano B (1998). Development of microglia in the postnatal rat hippocampus. Hippocampus 8: 458-474.

Dantzer R, O'Connor JC, Freund GG, Johnson RW, Kelley KW (2008). From inflammation to sickness and depression: when the immune system subjugates the brain. Nat Rev Neurosci 9: 46-56.

Daynes RA, Araneo BA, Ershler WB, Maloney C, Li GZ, Ryu SY (1993). Altered regulation of IL-6 production with normal aging. Possible linkage to the ageassociated decline in dehydroepiandrosterone and its sulfated derivative. $\mathrm{J}$ Immunol 150: 5219-5230.

De Bosscher K, Vanden Berghe W, Haegeman G (2003). The interplay between the glucocorticoid receptor and nuclear factor-kappaB or activator protein-1: molecular mechanisms for gene repression. Endocr Rev 24: 488-522.

De Kock M, Loix S, Lavand'homme P (2013). Ketamine and peripheral inflammation. CNS Neurosci Ther 19: 403-410.

Dickens C, McGowan L, Clark-Carter D, Creed F (2002). Depression in rheumatoid arthritis: a systematic review of the literature with meta-analysis. Psychosom Med 64: 52-60.

Domercq M, Brambilla L, Pilati E, Marchaland J, Volterra A, Bezzi P (2006). P2Y1 receptor-evoked glutamate exocytosis from astrocytes: control by tumor necrosis factor-alpha and prostaglandins. J Biol Chem 281: 30684-30696.

Dowlati Y, Herrmann N, Swardfager W, Liu H, Sham L, Reim EK et al (2010). A metaanalysis of cytokines in major depression. Biol Psychiatry 67: 446-457.

Eller T, Vasar V, Shlik J, Maron E (2008). Pro-inflammatory cytokines and treatment response to escitalopram in major depressive disorder. Prog Neuropsychopharmacol Biol Psychiatry 32: 445-450.

Eyre HA, Air T, Proctor S, Rositano S, Baune BT (2015). A critical review of the efficacy of non-steroidal anti-inflammatory drugs in depression. Prog Neuropsychopharmacol Biol Psychiatry 57: 11-16.

Fagundes CP, Glaser R, Hwang BS, Malarkey WB, Kiecolt-Glaser JK (2013). Depressive symptoms enhance stress-induced inflammatory responses. Brain Behav Immun 31: 172-176.

Felger JC, Haroon E, Woolwine BJ, Raison CL, Miller AH (2015a). Interferon-alphainduced inflammation is associated with reduced glucocorticoid negative feedback sensitivity and depression in patients with hepatitis $\mathrm{C}$ virus. Physiol Behav. pii: S0031-9384(15)30210-9.

Felger JC, Li Z, Haroon E, Woolwine BJ, Jung MY, Hu X et al (2015b). Inflammation is associated with decreased functional connectivity within corticostriatal reward circuitry in depression. Mol Psychiatry (e-pub ahead of print).

Fenton WS, Stover ES (2006). Mood disorders: cardiovascular and diabetes comorbidity. Curr Opin Psychiatry 19: 421-427.

Fiedorowicz JG, Prossin AR, Johnson CP, Christensen GE, Magnotta VA, Wemmie JA (2015). Peripheral inflammation during abnormal mood states in bipolar I disorder. J Affect Disord 187: 172-178.

Fornaro M, Rocchi G, Escelsior A, Contini P, Martino M (2013). Might different cytokine trends in depressed patients receiving duloxetine indicate differential biological backgrounds. J Affect Disord 145: 300-307.

Frank MG, Baratta MV, Sprunger DB, Watkins LR, Maier SF (2007). Microglia serve as a neuroimmune substrate for stress-induced potentiation of CNS pro-inflammatory cytokine responses. Brain Behav Immun 21: 47-59. This paper reported that isolated microglia from rodents vulnerable to stress produce higher levels of pro-inflammatory cytokines following LPS stimulation when compared to those of unstressed controls suggesting that stress could exacerbated microglia sensitivity.

Frank MG, Watkins LR, Maier SF (2013). Stress-induced glucocorticoids as a neuroendocrine alarm signal of danger. Brain Behav Immun 33: 1-6.

Frank MG, Weber MD, Watkins LR, Maier SF (2015). Stress sounds the alarmin: the role of the danger-associated molecular pattern HMGB1 in stress-induced neuroinflammatory priming. Brain Behav Immun 48: 1-7.

Frasch A, Zetzsche T, Steiger A, Jirikowski GF (1995). Reduction of plasma oxytocin levels in patients suffering from major depression. Adv Exp Med Biol 395: 257-258

Galea LA, McEwen BS, Tanapat P, Deak T, Spencer RL, Dhabhar FS (1997). Sex differences in dendritic atrophy of CA3 pyramidal neurons in response to chronic restraint stress. Neuroscience 81: 689-697.

Garmezy N (1971). Vulnerability research and the issue of primary prevention. Am J Orthopsychiatry 41: 101-116.

Gill J, Vythilingam M, Page GG (2008). Low cortisol, high DHEA, and high levels of stimulated TNF-alpha, and IL-6 in women with PTSD. J Trauma Stress 21: 530-539.

Ginhoux F, Greter M, Leboeuf M, Nandi S, See P, Gokhan S et al (2010). Fate mapping analysis reveals that adult microglia derive from primitive macrophages. Science 330: 841-845. 
Ginhoux F, Jung S (2014). Monocytes and macrophages: developmental pathways and tissue homeostasis. Nat Rev Immunol 14: 392-404.

Golden SA, Covington HE 3rd, Berton O, Russo SJ (2011). A standardized protocol for repeated social defeat stress in mice. Nat Protoc 6: 1183-1191.

Goldstein BI, Kemp DE, Soczynska JK, Mclntyre RS (2009). Inflammation and the phenomenology, pathophysiology, comorbidity, and treatment of bipolar disorder: a systematic review of the literature. J Clin Psychiatry 70: 1078-1090.

Goldstein DS, McEwen B (2002). Allostasis, homeostats, and the nature of stress. Stress 5: 55-58.

Gorski RA, Gordon JH, Shryne JE, Southam AM (1978). Evidence for a morphological sex difference within the medial preoptic area of the rat brain. Brain Res 148: 333-346.

Grippo AJ, Francis J, Beltz TG, Felder RB, Johnson AK (2005). Neuroendocrine and cytokine profile of chronic mild stress-induced anhedonia. Physiol Behav 84: 697-706

Grippo AJ, Trahanas DM, Zimmerman RR 2nd, Porges SW, Carter CS (2009). Oxytocin protects against negative behavioral and autonomic consequences of long-term social isolation. Psychoneuroendocrinology 34: 1542-1553.

Hamby ME, Coppola G, Ao Y, Geschwind DH, Khakh BS, Sofroniew MV (2012). Inflammatory mediators alter the astrocyte transcriptome and calcium signaling elicited by multiple G-protein-coupled receptors. J Neurosci 32: 14489-14510.

Hanamsagar R, Bilbo SD (2015). Sex differences in neurodevelopmental and neurodegenerative disorders: Focus on microglial function and neuroinflammation during development. J Steroid Biochem Mol Biol 160: 127-133.

Harrison JK, Jiang Y, Chen S, Xia Y, Maciejewski D, McNamara RK et al (1998). Role for neuronally derived fractalkine in mediating interactions between neurons and CX3CR1-expressing microglia. Proc Natl Acad Sci USA 95: 10896-10901.

Heidt T, Sager HB, Courties G, Dutta P, Iwamoto Y, Zaltsman A et al (2014). Chronic variable stress activates hematopoietic stem cells. Nat Med 20: 754-758.

Heim C, Young LJ, Newport DJ, Mletzko T, Miller AH, Nemeroff CB (2009). Lower CSF oxytocin concentrations in women with a history of childhood abuse. Mol Psychiatry 14: 954-958.

Hellwig S, Brioschi S, Dieni S, Frings L, Masuch A, Blank T et al (2015). Altered microglia morphology and higher resilience to stress-induced depression-like behavior in CX3CR1-deficient mice. Brain Behav Immun 55: 126-137. This study suggests a role for microglia hyper-ramification and CX3CR1 in the etiology of depression.

Hernandez ME, Mendieta D, Martinez-Fong D, Loria F, Moreno J, Estrada I et al (2008). Variations in circulating cytokine levels during 52 week course of treatment with SSRI for major depressive disorder. Eur Neuropsychopharmacol 18: 917-924.

Hinwood M, Tynan RJ, Charnley JL, Beynon SB, Day TA, Walker FR (2013). Chronic stress induced remodeling of the prefrontal cortex: structural re-organization of microglia and the inhibitory effect of minocycline. Cereb Cortex 23: 1784-1797.

Hodes GE (2013). Sex, stress, and epigenetics: regulation of behavior in animal models of mood disorders. Biol Sex Differ 4: 1.

Hodes GE, Kana V, Menard C, Merad M, Russo SJ (2015a). Neuroimmune mechanisms of depression. Nat Neurosci 18: 1386-1393.

Hodes GE, Pfau ML, Leboeuf M, Golden SA, Christoffel DJ, Bregman D et al (2014). Individual differences in the peripheral immune system promote resilience versus susceptibility to social stress. Proc Natl Acad Sci USA 111: 16136-16141. This paper proposes that differences in the innate peripheral immune system, notably the number of circulating leukocytes and leukocyte IL-6 release following LPS stimulation, can predict susceptibility or resilience to chronic social defeat stress.

Hodes GE, Pfau ML, Purushothaman I, Ahn HF, Golden SA, Christoffel DJ et al (2015b). Sex differences in nucleus accumbens transcriptome profiles associated with susceptibility versus resilience to subchronic variable stress. J Neurosci 35: 16362-16376. This study suggests a role for hypothalamic-pituitary-adrenal axis regulation in sex differences in stress vulnerability.

Hsu B, Wang D, Sun Y, Salvadore G, Singh J, Curran M et al (2015). Improvement in measures of depressed mood and anhedonia, and fatigue, in a randomized, placebo-controlled, phase 2 study of sirukumab, a human anti-interleukin-6 antibody, in patients with rheumatoid arthritis. Ann Rheum Dis 74(Suppl 2): 720-721

Hu Q, Zhang SY, Liu F, Zhang YL, Zhu DM, Zang YY (2015). Clinical significance of decreased protein expression of dehydroepiandrosterone sulfate in the development of depression: a meta-analysis. J Affect Disord 174: 416-423.

Hua JY, Smith SJ (2004). Neural activity and the dynamics of central nervous system development. Nat Neurosci 7: 327-332.

Huang TL, Lee CT (2007). T-helper 1/T-helper 2 cytokine imbalance and clinical phenotypes of acute-phase major depression. Psychiatry Clin Neurosci 61: $415-420$.
Hung CC, Lin CH, Chang H, Wang CY, Lin SH, Hsu PC et al (2016). Astrocytic GAP43 induced by the TLR4/NF-kappaB/STAT3 axis attenuates astrogliosis-mediated microglial activation and neurotoxicity. J Neurosci 36: 2027-2043

Iwata M, Ota KT, Duman RS (2013). The inflammasome: pathways linking psychological stress, depression, and systemic illnesses. Brain Behav Immun 31 105-114.

Iwata M, Ota KT, Li XY, Sakaue F, Li N, Dutheil S et al (2015). Psychological stress activates the inflammasome via release of adenosine triphosphate and stimulation of the purinergic type $2 X 7$ receptor. Biol Psychiatry 80: 12-22. This study shows that the activated microglia inflammasome is involved in the development of depression-like behaviors.

lyengar RL, Gandhi S, Aneja A, Thorpe K, Razzouk L, Greenberg J et al (2013). NSAIDs are associated with lower depression scores in patients with osteoarthritis. Am J Med 126: 1017 e1011-1017 e1018.

Jazayeri S, Keshavarz SA, Tehrani-Doost M, Djalali M, Hosseini M, Amini $\mathrm{H}$ et al (2010). Effects of eicosapentaenoic acid and fluoxetine on plasma cortisol, serum interleukin-1beta and interleukin-6 concentrations in patients with major depressive disorder. Psychiatry Res 178: 112-115.

Jiang M, Qin P, Yang X (2014). Comorbidity between depression and asthma via immune-inflammatory pathways: a meta-analysis. J Affect Disord 166: 22-29.

Kalelioglu T, Akkus M, Karamustafalioglu N, Genc A, Genc ES, Cansiz A et al (2015). Neutrophil-lymphocyte and platelet-lymphocyte ratios as inflammation markers for bipolar disorder. Psychiatry Res 228: 925-927.

Kapczinski F, Dal-Pizzol F, Teixeira AL, Magalhaes PV, Kauer-Sant'Anna M, Klamt F et al (2011). Peripheral biomarkers and illness activity in bipolar disorder. J Psychiatr Res 45: 156-161.

Katz LC, Shatz CJ (1996). Synaptic activity and the construction of cortical circuits. Science 274: 1133-1138.

Kearns MC, Ressler KJ, Zatzick D, Rothbaum BO (2012). Early interventions for PTSD: a review. Depress Anxiety 29: 833-842.

Kessler RC, Chiu WT, Demler O, Merikangas KR, Walters EE (2005). Prevalence, severity, and comorbidity of 12-month DSM-IV disorders in the National Comorbidity Survey Replication. Arch Gen Psychiatry 62: 617-627.

Kessler RC, McGonagle KA, Swartz M, Blazer DG, Nelson CB (1993). Sex and depression in the National Comorbidity Survey. I: lifetime prevalence, chronicity and recurrence. J Affect Disord 29: 85-96.

Kessler RC, McGonagle KA, Zhao S, Nelson CB, Hughes M, Eshleman S et al (1994). Lifetime and 12-month prevalence of DSM-III-R psychiatric disorders in the United States. Results from the National Comorbidity Survey. Arch Gen Psychiatry 51: 8-19.

Kessler RC, van Loo HM, Wardenaar KJ, Bossarte RM, Brenner LA, Ebert DD et al (2016). Using patient self-reports to study heterogeneity of treatment effects in major depressive disorder. Epidemiol Psychiatr Sci 1-15.

Kim YK, Suh IB, Kim H, Han CS, Lim CS, Choi SH et al (2002). The plasma levels of interleukin-12 in schizophrenia, major depression, and bipolar mania: effects of psychotropic drugs. Mol Psychiatry 7: 1107-1114.

Kirschbaum C, Prussner JC, Stone AA, Federenko I, Gaab J, Lintz D et al (1995). Persistent high cortisol responses to repeated psychological stress in a subpopulation of healthy men. Psychosom Med 57: 468-474.

Kitraki E, Kremmyda O, Youlatos D, Alexis MN, Kittas C (2004). Gender-dependent alterations in corticosteroid receptor status and spatial performance following 21 days of restraint stress. Neuroscience 125: 47-55

Kohler O, Benros ME, Nordentoft M, Farkouh ME, lyengar RL, Mors O et al (2014). Effect of anti-inflammatory treatment on depression, depressive symptoms, and adverse effects: a systematic review and meta-analysis of randomized clinical trials. JAMA Psychiatry 71: 1381-1391. This meta-analysis reveals the antidepressant effects and potential benefits to treat major depressive disorder of selective COX-2 inhibitor celecoxib.

Koo JW, Duman RS (2008). IL-1beta is an essential mediator of the antineurogenic and anhedonic effects of stress. Proc Natl Acad Sci USA 105: 751-756.

Korn T, Bettelli E, Oukka M, Kuchroo VK (2009). IL-17 and Th17 Cells. Annu Rev Immunol 27: 485-517.

Kreisel T, Frank MG, Licht T, Reshef R, Ben-Menachem-Zidon O, Baratta MV et al (2014). Dynamic microglial alterations underlie stress-induced depressive-like behavior and suppressed neurogenesis. Mol Psychiatry 19: 699-709.

Krishnan V, Han MH, Graham DL, Berton O, Renthal W, Russo SJ et al (2007). Molecular adaptations underlying susceptibility and resistance to social defeat in brain reward regions. Cell 131: 391-404.

Krishnan V, Nestler EJ (2008). The molecular neurobiology of depression. Nature 455: 894-902.

Kubera M, Kenis G, Bosmans E, Kajta M, Basta-Kaim A, Scharpe S et al (2004). Stimulatory effect of antidepressants on the production of IL-6. Int Immunopharmacol 4: 185-192. 
Lanquillon S, Krieg JC, Bening-Abu-Shach U, Vedder H (2000). Cytokine production and treatment response in major depressive disorder. Neuropsychopharmacology 22: 370-379.

Laye S, Parnet P, Goujon E, Dantzer R (1994). Peripheral administration of lipopolysaccharide induces the expression of cytokine transcripts in the brain and pituitary of mice. Brain Res Mol Brain Res 27: 157-162.

Lee KM, Kim YK (2006). The role of IL-12 and TGF-beta1 in the pathophysiology of major depressive disorder. Int Immunopharmacol 6: 1298-1304.

Lee HB, Lyketsos CG (2003). Depression in Alzheimer's disease: heterogeneity and related issues. Biol Psychiatry 54: 353-362.

Lenz KM, McCarthy MM (2015). A starring role for microglia in brain sex differences. Neuroscientist 21: 306-321.

Lenz KM, Nugent BM, Haliyur R, McCarthy MM (2013). Microglia are essential to masculinization of brain and behavior. J Neurosci 33: 2761-2772.

Leo R, Di Lorenzo G, Tesauro M, Razzini C, Forleo GB, Chiricolo G et al (2006). Association between enhanced soluble CD40 ligand and proinflammatory and prothrombotic states in major depressive disorder: pilot observations on the effects of selective serotonin reuptake inhibitor therapy. J Clin Psychiatry 67: 1760-1766.

Lewitus GM, Schwartz M (2009a). Behavioral immunization: immunity to selfantigens contributes to psychological stress resilience. Mol Psychiatry 14: 532-536.

Lewitus GM, Wilf-Yarkoni A, Ziv Y, Shabat-Simon M, Gersner R, Zangen A et al (2009b). Vaccination as a novel approach for treating depressive behavior. Biol Psychiatry 65: 283-288.

Liu HC, Yang YY, Chou YM, Chen KP, Shen WW, Leu SJ (2004). Immunologic variables in acute mania of bipolar disorder. J Neuroimmunol 150: 116-122.

Lopez AD, Murray CC (1998). The global burden of disease, 1990-2020. Nat Med 4: 1241-1243.

Louveau A, Smirnov I, Keyes TJ, Eccles JD, Rouhani SJ, Peske JD et al (2015). Structural and functional features of central nervous system lymphatic vessels. Nature 523: 337-341.

Luppino FS, de Wit LM, Bouvy PF, Stijnen T, Cuijpers P, Penninx BW et al (2010). Overweight, obesity, and depression: a systematic review and meta-analysis of longitudinal studies. Arch Gen Psychiatry 67: 220-229.

Maes M (1995). Evidence for an immune response in major depression: a review and hypothesis. Prog Neuropsychopharmacol Biol Psychiatry 19: 11-38.

Maes M, Bosmans E, De Jongh R, Kenis G, Vandoolaeghe E, Neels H (1997). Increased serum IL-6 and IL-1 receptor antagonist concentrations in major depression and treatment resistant depression. Cytokine 9: 853-858.

Maes M, Bosmans E, Meltzer HY, Scharpe S, Suy E (1993). Interleukin-1 beta: a putative mediator of HPA axis hyperactivity in major depression? Am J Psychiatry 150: 1189-1193.

Maes M, Kubera M, Obuchowiczwa E, Goehler L, Brzeszcz J (2011). Depression's multiple comorbidities explained by (neuro)inflammatory and oxidative and nitrosative stress pathways. Neuro Endocrinol Lett 32: 7-24.

Maes M, Meltzer HY, Bosmans E, Bergmans R, Vandoolaeghe E, Ranjan R et al (1995a). Increased plasma concentrations of interleukin-6, soluble interleukin-6, soluble interleukin-2 and transferrin receptor in major depression. J Affect Disord 34: 301-309. This paper is the first to report that IL-6 and its receptor may represent a trait marker of major depressive disorder.

Maes M, Van der Planken M, Stevens WJ, Peeters D, DeClerck LS, Bridts CH et al (1992). Leukocytosis, monocytosis and neutrophilia: hallmarks of severe depression. J Psychiatr Res 26: 125-134.

Maes M, Vandoolaeghe E, Ranjan R, Bosmans E, Bergmans R, Desnyder R (1995b). Increased serum interleukin-1-receptor-antagonist concentrations in major depression. J Affect Disord 36: 29-36.

Maier SF (1990). Role of fear in mediating shuttle escape learning deficit produced by inescapable shock. J Exp Psychol Anim Behav Process 16: 137-149.

Maier SF, Watkins LR (1995). Intracerebroventricular interleukin-1 receptor antagonist blocks the enhancement of fear conditioning and interference with escape produced by inescapable shock. Brain Res 695: 279-282.

Marrie RA, Reingold S, Cohen J, Stuve O, Trojano M, Sorensen PS et al (2015). The incidence and prevalence of psychiatric disorders in multiple sclerosis: a systematic review. Mult Scler 21: 305-317.

Martin LA, Neighbors HW, Griffith DM (2013). The experience of symptoms of depression in men vs women: analysis of the National Comorbidity Survey Replication. JAMA Psychiatry 70: 1100-1106.

Mason DR, Beck PL, Muruve DA (2012). Nucleotide-binding oligomerization domain-like receptors and inflammasomes in the pathogenesis of non-microbial inflammation and diseases. J Innate Immun 4: 16-30.

Masten AS (2001). Ordinary magic. Resilience processes in development. Am Psychol 56: 227-238.

Matcham F, Rayner L, Steer S, Hotopf M (2014). The prevalence of depression in rheumatoid arthritis: a systematic review and meta-analysis: reply. Rheumatology (Oxford) 53: 578-579.
Maurer J, Rebbapragada V, Borson S, Goldstein R, Kunik ME, Yohannes AM et al (2008). Anxiety and depression in COPD: current understanding, unanswered questions, and research needs. Chest 134(4 Suppl): 43S-56S.

McEwen BS, Gray JD, Nasca C (2015). 60 Years of neuroendocrinology: redefining neuroendocrinology: stress, sex and cognitive and emotional regulation. J Endocrinol 226: T67-T83.

McQuaid RJ, Mclnnis OA, Abizaid A, Anisman H (2014). Making room for oxytocin in understanding depression. Neurosci Biobehav Rev 45: 305-322.

Meeuwsen S, Persoon-Deen C, Bsibsi M, Ravid R, van Noort JM (2003). Cytokine, chemokine and growth factor gene profiling of cultured human astrocytes after exposure to proinflammatory stimuli. Glia 43: 243-253.

Menard C, Hodes GE, Russo SJ (2016). Pathogenesis of depression: insights from human and rodent studies. Neuroscience 321: 138-162.

Mikova O, Yakimova R, Bosmans E, Kenis G, Maes M (2001). Increased serum tumor necrosis factor alpha concentrations in major depression and multiple sclerosis. Eur Neuropsychopharmacol 11: 203-208.

Miller AH (2010). Depression and immunity: a role for T cells? Brain Behav Immun 24: $1-8$

Miller AH, Raison CL (2015). The role of inflammation in depression: from evolutionary imperative to modern treatment target. Nat Rev Immunol 16: 22-34.

Miller GE, Chen E, Sze J, Marin T, Arevalo JM, Doll R et al (2008). A functional genomic fingerprint of chronic stress in humans: blunted glucocorticoid and increased NF-kappaB signaling. Biol Psychiatry 64: 266-272.

Miller GE, Rohleder N, Stetler C, Kirschbaum C (2005). Clinical depression and regulation of the inflammatory response during acute stress. Psychosom Med 67: 679-687. This paper reported prolonged inflammatory response under acutely challenging conditions in depressed women compared to healthy individuals.

Moieni M, Irwin MR, Jevtic I, Olmstead R, Breen EC, Eisenberger NI (2015). Sex differences in depressive and socioemotional responses to an inflammatory challenge: implications for sex differences in depression. Neuropsychopharmacology 40: 1709-1716.

Moussavi S, Chatterii S, Verdes E, Tandon A, Patel V, Ustun B (2007). Depression, chronic diseases, and decrements in health: results from the World Health Surveys. Lancet 370: 851-858.

Mueller BR, Bale TL (2008). Sex-specific programming of offspring emotionality after stress early in pregnancy. J Neurosci 28: 9055-9065.

Mueller SN, Mackay LK (2016). Tissue-resident memory T cells: local specialists in immune defence. Nat Rev Immunol 16: 79-89.

Munkholm K, Weikop P, Kessing LV, Vinberg M (2015). Elevated levels of IL-6 and $\mathrm{IL}-18$ in manic and hypomanic states in rapid cycling bipolar disorder patients. Brain Behav Immun 43: 205-213.

Munzer A, Sack U, Mergl R, Schonherr J, Petersein C, Bartsch S et al (2013). Impact of antidepressants on cytokine production of depressed patients in vitro Toxins (Basel) 5(11): 2227-2240

Murrough JW, losifescu DV, Chang LC, Al Jurdi RK, Green CE, Perez AM et al (2013a). Antidepressant efficacy of ketamine in treatment-resistant major depression: a two-site randomized controlled trial. Am J Psychiatry 170: 1134-1142.

Murrough JW, Perez AM, Pillemer S, Stern J, Parides MK, aan het Rot M et al (2013b). Rapid and longer-term antidepressant effects of repeated ketamine infusions in treatment-resistant major depression. Biol Psychiatry 74: 250-256.

Mutlu O, Gumuslu E, Ulak G, Celikyurt IK, Kokturk S, Kir HM et al (2012). Effects of fluoxetine, tianeptine and olanzapine on unpredictable chronic mild stressinduced depression-like behavior in mice. Life Sci 91: 1252-1262.

Nanni MG, Caruso R, Mitchell AJ, Meggiolaro E, Grassi L (2015). Depression in HIV infected patients: a review. Curr Psychiatry Rep 17: 530.

Nery FG, Borba EF, Hatch JP, Soares JC, Bonfa E, Neto FL (2007). Major depressive disorder and disease activity in systemic lupus erythematosus. Compr Psychiatry 48: 14-19.

Newton TL, Fernandez-Botran R, Miller JJ, Burns VE (2014). Interleukin-6 and soluble interleukin-6 receptor levels in posttraumatic stress disorder: associations with lifetime diagnostic status and psychological context. Biol Psychol 99: 150-159.

Nimmerjahn A, Kirchhoff F, Helmchen F (2005). Resting microglial cells are highly dynamic surveillants of brain parenchyma in vivo. Science 308: 1314-1318.

Norman GJ, Karelina K, Morris JS, Zhang N, Cochran M, Courtney DeVries A (2010). Social interaction prevents the development of depressive-like behavior post nerve injury in mice: a potential role for oxytocin. Psychosom Med 72 : $519-526$.

Opacka-Juffry J, Mohiyeddini C (2012). Experience of stress in childhood negatively correlates with plasma oxytocin concentration in adult men. Stress 15: 1-10.

Owen BM, Eccleston D, Ferrier IN, Young AH (2001). Raised levels of plasma interleukin-1beta in major and postviral depression. Acta Psychiatr Scand 103: 226-228. 
Ozsoy S, Esel E, Kula M (2009). Serum oxytocin levels in patients with depression and the effects of gender and antidepressant treatment. Psychiatry Res 169: 249-252.

Panenka W, Jijon H, Herx LM, Armstrong JN, Feighan D, Wei T et al (2001). P2X7-like receptor activation in astrocytes increases chemokine monocyte chemoattractant protein-1 expression via mitogen-activated protein kinase. J Neurosci 21: 7135-7142.

Pang Y, Cai Z, Rhodes PG (2001). Analysis of genes differentially expressed in astrocytes stimulated with lipopolysaccharide using cDNA arrays. Brain Res 914: $15-22$

Paolicelli RC, Bolasco G, Pagani F, Maggi L, Scianni M, Panzanelli P et al (2011). Synaptic pruning by microglia is necessary for normal brain development. Science 333: 1456-1458.

Parker KJ, Kenna HA, Zeitzer JM, Keller J, Blasey CM, Amico JA et al (2010). Preliminary evidence that plasma oxytocin levels are elevated in major depression. Psychiatry Res 178: 359-362.

Passos IC, Vasconcelos-Moreno MP, Costa LG, Kunz M, Brietzke E, Quevedo J et al (2015). Inflammatory markers in post-traumatic stress disorder: a systematic review, meta-analysis, and meta-regression. Lancet Psychiatry 2: 1002-1012.

Pfau ML, Russo SJ (2015). Peripheral and central mechanisms of stress resilience. Neurobiol Stress 1: 66-79.

Plotsky PM, Meaney MJ (1993). Early, postnatal experience alters hypothalamic corticotropin-releasing factor (CRF) mRNA, median eminence CRF content and stress-induced release in adult rats. Brain Res Mol Brain Res 18: 195-200.

Portou MJ, Baker D, Abraham D, Tsui J (2015). The innate immune system, toll-like receptors and dermal wound healing: a review. Vascul Pharmacol 71: 31-36

Powell ND, Sloan EK, Bailey MT, Arevalo JM, Miller GE, Chen E et al (2013). Social stress up-regulates inflammatory gene expression in the leukocyte transcriptome via beta-adrenergic induction of myelopoiesis. Proc Natl Acad Sci USA 110: 16574-16579. This study associates enhanced immature proinflammatory monocyte production to social stress in mice and humans.

Quan N, Stern EL, Whiteside MB, Herkenham M (1999). Induction of proinflammatory cytokine mRNAs in the brain after peripheral injection of subseptic doses of lipopolysaccharide in the rat. J Neuroimmunol 93: 72-80.

Raison CL, Rutherford RE, Woolwine BJ, Shuo C, Schettler P, Drake DF et al (2013). A randomized controlled trial of the tumor necrosis factor antagonist infliximab for treatment-resistant depression: the role of baseline inflammatory biomarkers. JAMA Psychiatry 70: 31-41. This paper reports the results of a double-blind, placebo-controlled randomized clinical trial assessing the efficacy of infliximab, a chimeric monoclonal antibody against pro-inflammatory cytokine TNF $\alpha$, to treat depressive symptoms

Ransohoff RM, Brown MA (2012). Innate immunity in the central nervous system. J Clin Invest 122: 1164-1171.

Ransohoff RM, Tani M (1998). Do chemokines mediate leukocyte recruitment in post-traumatic CNS inflammation? Trends Neurosci 21: 154-159.

Rasmusson AM, Vythilingam M, Morgan CA 3rd (2003). The neuroendocrinology of posttraumatic stress disorder: new directions. CNS Spectr 8: 651-656 665-657

Renault PF, Hoofnagle JH, Park Y, Mullen KD, Peters M, Jones DB et al (1987). Psychiatric complications of long-term interferon alfa therapy. Arch Intern Med 147: 1577-1580.

Ridet JL, Malhotra SK, Privat A, Gage FH (1997). Reactive astrocytes: cellular and molecular cues to biological function. Trends Neurosci 20: 570-577.

Rogers JT, Morganti JM, Bachstetter AD, Hudson CE, Peters MM, Grimmig BA et al (2011). CX3CR1 deficiency leads to impairment of hippocampal cognitive function and synaptic plasticity. J Neurosci 31: 16241-16250.

Rosenblat JD, Cha DS, Mansur RB, McIntyre RS (2014). Inflamed moods: a review of the interactions between inflammation and mood disorders. Prog Neuropsychopharmacol Biol Psychiatry 53: 23-34.

Rudisch B, Nemeroff CB (2003). Epidemiology of comorbid coronary artery disease and depression. Biol Psychiatry 54: 227-240.

Russo SJ, Murrough JW, Han MH, Charney DS, Nestler EJ (2012). Neurobiology of resilience. Nat Neurosci 15: 1475-1484.

Russo SJ, Nestler EJ (2013). The brain reward circuitry in mood disorders. Nat Rev Neurosci 14: 609-625.

Sanches M, Zunta-Soares GB, Hatch JP, Soares JC (2013). Gender differences in serum cortisol levels among patients with major depressive disorder. Neuropsychatria Neuropsychologia 8: 89-93.

Sasayama D, Hattori K. Teraishi T, Hori H, Ota M, Yoshida S et al (2012). Negative correlation between cerebrospinal fluid oxytocin levels and negative symptoms of male patients with schizophrenia. Schizophr Res 139: 201-206.

Scantamburlo G, Hansenne M, Fuchs S, Pitchot W, Marechal P, Pequeux C et al (2007). Plasma oxytocin levels and anxiety in patients with major depression. Psychoneuroendocrinology 32: 407-410.
Schelling G, Roozendaal B, Krauseneck T, Schmoelz M, DE Quervain D, Briegel J (2006). Efficacy of hydrocortisone in preventing posttraumatic stress disorder following critical illness and major surgery. Ann N Y Acad Sci 1071: 46-53.

Schwartz JM, Sholar PW, Bilbo SD (2012). Sex differences in microglial colonization of the developing rat brain. J Neurochem 120: 948-963.

Seligman F, Nemeroff CB (2015). The interface of depression and cardiovascular disease: therapeutic implications. Ann N Y Acad Sci 1345: 25-35.

Shechter R, London A, Schwartz M (2013). Orchestrated leukocyte recruitment to immune-privileged sites: absolute barriers versus educational gates. Nat Rev Immunol 13: 206-218.

Shi C, Pamer EG. (2011). Monocyte recruitment during infection and inflammation. Nat Rev Immunol 11: 762-774.

Sica A, Wang JM, Colotta F, Dejana E, Mantovani A, Oppenheim JJ et al (1990). Monocyte chemotactic and activating factor gene expression induced in endothelial cells by $\mathrm{IL}-1$ and tumor necrosis factor. J Immunol 144 3034-3038.

Siegert RJ, Abernethy DA (2005). Depression in multiple sclerosis: a review. J Neurol Neurosurg Psychiatry 76: 469-475.

Simon NM, McNamara K, Chow CW, Maser RS, Papakostas GI, Pollack MH et al (2008). A detailed examination of cytokine abnormalities in major depressive disorder. Eur Neuropsychopharmacol 18: 230-233.

Slattery DA, Cryan JF (2014). The ups and downs of modelling mood disorders in rodents. ILAR J 55: 297-309.

Sluzewska A, Rybakowski J, Bosmans E, Sobieska M, Berghmans R, Maes M et al (1996). Indicators of immune activation in major depression. Psychiatry Res 64 161-167.

Sluzewska A, Rybakowski JK, Laciak M, Mackiewicz A, Sobieska M, Wiktorowicz K (1995). Interleukin-6 serum levels in depressed patients before and after treatment with fluoxetine. Ann N Y Acad Sci 762: 474-476.

Smith RS (1991). The macrophage theory of depression. Med Hypotheses 35 298-306. This report proposes the macrophage theory of depression to explain the higher prevalence of depression in patients suffering from inflammatory diseases.

Sofroniew MV (2009). Molecular dissection of reactive astrogliosis and glial scar formation. Trends Neurosci 32: 638-647.

Sofroniew MV (2014). Multiple roles for astrocytes as effectors of cytokines and inflammatory mediators. Neuroscientist 20: 160-172.

Stark JL, Avitsur R, Padgett DA, Campbell KA, Beck FM, Sheridan JF (2001). Social stress induces glucocorticoid resistance in macrophages. Am J Physiol Regul Integr Comp Physiol 280: R1799-R1805.

Stetler C, Miller GE (2011). Depression and hypothalamic-pituitary-adrenal activation: a quantitative summary of four decades of research. Psychosom Med 73: 114-126. This meta-analysis of clinical studies confirms an association between hypothalamic-pituitary-adrenal axis hyperactivity and depression.

Stevens B, Allen NJ, Vazquez LE, Howell GR, Christopherson KS, Nouri N et al (2007). The classical complement cascade mediates CNS synapse elimination. Cell 131: 1164-1178.

Straub RH, Buttgereit F, Cutolo M (2011). Alterations of the hypothalamic-pituitaryadrenal axis in systemic immune diseases - a role for misguided energy regulation. Clin Exp Rheumatol 29(Suppl 68): S23-S31.

Straub RH, Konecna L, Hrach S, Rothe G, Kreutz M, Scholmerich J et al (1998). Serum dehydroepiandrosterone (DHEA) and DHEA sulfate are negatively correlated with serum interleukin-6 (IL-6), and DHEA inhibits IL-6 secretion from mononuclear cells in man in vitro: possible link between endocrinosenescence and immunosenescence. J Clin Endocrinol Metab 83: 2012-2017.

Stunkard AJ, Faith MS, Allison KC (2003). Depression and obesity. Biol Psychiatry 54: 330-337.

Su SC, Sun MT, Wen MJ, Lin CJ, Chen YC, Hung YJ (2011). Brain-derived neurotrophic factor, adiponectin, and proinflammatory markers in various subtypes of depression in young men. Int J Psychiatry Med 42: 211-226.

Suarez EC, Sundy JS, Erkanli A (2015). Depressogenic vulnerability and genderspecific patterns of neuro-immune dysregulation: What the ratio of cortisol to C-reactive protein can tell us about loss of normal regulatory control. Brain Behav Immun 44: 137-147. This study proposes to compare corticosterone to c-reactive protein ratio to indicate the efficiency of homeostatic hypothalamic-pituitary-adrenal axis response versus immune regulatory mechanisms and predict vulnerability to major depressive disorder.

Suris A, North C, Adinoff B, Powell CM, Greene R (2010). Effects of exogenous glucocorticoid on combat-related PTSD symptoms. Ann Clin Psychiatry 22 274-279.

Sutcigil L, Oktenli C, Musabak U, Bozkurt A, Cansever A, Uzun O et al (2007). Pro- and anti-inflammatory cytokine balance in major depression: effect of sertraline therapy. Clin Dev Immunol 2007: 76396.

Taylor MK, Padilla GA, Stanfill KE, Markham AE, Khosravi JY, Ward MD et al (2012). Effects of dehydroepiandrosterone supplementation during stressful 
military training: a randomized, controlled, double-blind field study. Stress 15: 85-96.

Torres-Platas SG, Cruceanu C, Chen GG, Turecki G, Mechawar N (2014). Evidence for increased microglial priming and macrophage recruitment in the dorsal anterior cingulate white matter of depressed suicides. Brain Behav Immun 42: 50-59.

Traki L, Rostom S, Tahiri L, Bahiri R, Harzy T, Abouqal R et al (2014). Responsiveness of the EuroQol EQ-5D and Hospital Anxiety and Depression Scale (HADS) in rheumatoid arthritis patients receiving tocilizumab. Clin Rheumatol 33: 1055-1060.

Tremblay ME, Lowery RL, Majewska AK (2010). Microglial interactions with synapses are modulated by visual experience. PLoS Biol 8: e1000527.

Tremblay ME, Stevens B, Sierra A, Wake H, Bessis A, Nimmerjahn A (2011). The role of microglia in the healthy brain. J Neurosci 31: 16064-16069.

Tsai SY, Chen KP, Yang YY, Chen CC, Lee JC, Singh VK et al (1999). Activation of indices of cell-mediated immunity in bipolar mania. Biol Psychiatry 45: 989-994.

Tsai SY, Chung KH, Wu JY, Kuo CJ, Lee HC, Huang SH (2012). Inflammatory markers and their relationships with leptin and insulin from acute mania to full remission in bipolar disorder. J Affect Disord 136: 110-116.

Tsai SY, Lee HC, Chen CC, Lee CH (2003). Plasma levels of soluble transferrin receptors and Clara cell protein (CC16) during bipolar mania and subsequent remission. J Psychiatr Res 37: 229-235.

Tsai SY, Yang YY, Kuo CJ, Chen CC, Leu SJ (2001). Effects of symptomatic severity on elevation of plasma soluble interleukin-2 receptor in bipolar mania. $J$ Affect Disord 64: 185-193.

Tynan RJ, Naicker S, Hinwood M, Nalivaiko E, Buller KM, Pow DV et al (2010). Chronic stress alters the density and morphology of microglia in a subset of stress-responsive brain regions. Brain Behav Immun 24: 1058-1068.

Tynan RJ, Weidenhofer J, Hinwood M, Cairns MJ, Day TA, Walker FR (2012). A comparative examination of the anti-inflammatory effects of SSRI and SNRI antidepressants on LPS stimulated microglia. Brain Behav Immun 26: 469-479.

Ulrich-Lai YM, Herman JP (2009). Neural regulation of endocrine and autonomic stress responses. Nat Rev Neurosci 10: 397-409.

Uyanik V, Tuglu C, Gorgulu Y, Kunduracilar H, Uyanik MS (2015). Assessment of cytokine levels and hs-CRP in bipolar I disorder before and after treatment. Psychiatry Res 228: 386-392.

van Dam AM, Brouns M, Louisse S, Berkenbosch F (1992). Appearance of interleukin-1 in macrophages and in ramified microglia in the brain of endotoxintreated rats: a pathway for the induction of non-specific symptoms of sickness? Brain Res 588: 291-296.

Veazey C, Aki SO, Cook KF, Lai EC, Kunik ME (2005). Prevalence and treatment of depression in Parkinson's disease. J Neuropsychiatry Clin Neurosci 17: 310-323.

Verma S, Nakaoke R, Dohgu S, Banks WA (2006). Release of cytokines by brain endothelial cells: a polarized response to lipopolysaccharide. Brain Behav Immun 20: 449-455.

Vogelzangs N, Duivis HE, Beekman AT, Kluft C, Neuteboom J, Hoogendijk W et al (2012). Association of depressive disorderrs, depression characteristics and antidepressant medication with inflammation. Transl Psychiatry 2: e79.

Wang P, Yang HP, Tian S, Wang L, Wang SC, Zhang F et al (2015a). Oxytocinsecreting system: A major part of the neuroendocrine center regulating immunologic activity. J Neuroimmunol 289: 152-161.

Wang S, Blazer DG (2015b). Depression and cognition in the elderly. Annu Rev Clin Psychol 11: 331-360.
Warner-Schmidt JL, Vanover KE, Chen EY, Marshall JJ, Greengard P (2011). Antidepressant effects of selective serotonin reuptake inhibitors (SSRIs) are attenuated by antiinflammatory drugs in mice and humans. Proc Natl Acad Sci USA 108: 9262-9267.

Weaver IC, Champagne FA, Brown SE, Dymov S, Sharma S, Meaney MJ et al (2005). Reversal of maternal programming of stress responses in adult offspring through methyl supplementation: altering epigenetic marking later in life. J Neurosci 25: 11045-11054. This study shows that DNA methylation level of the glucocorticoid receptor gene promoter can regulate stress-related glucocorticoid negative feedback and depressive-like behaviors in adulthood in rodents.

Weiss JM, Nath A, Major EO, Berman JW (1999). HIV-1 Tat induces monocyte chemoattractant protein-1-mediated monocyte transmigration across a model of the human blood-brain barrier and up-regulates CCR5 expression on human monocytes. J Immunol 163: 2953-2959.

Wetzel HH, Gehl CR, Dellefave-Castillo L, Schiffman JF, Shannon KM, Paulsen JS, Huntington Study Group (2011). Suicidal ideation in Huntington disease: the role of comorbidity. Psychiatry Res 188: 372-376.

Willrich MA, Murray DL, Snyder MR (2015). Tumor necrosis factor inhibitors: clinical utility in autoimmune diseases. Trans/ Res 165: 270-282.

Wohleb ES, Hanke ML, Corona AW, Powell ND, Stiner LM, Bailey MT et al (2011). Beta-adrenergic receptor antagonism prevents anxiety-like behavior and microglial reactivity induced by repeated social defeat. J Neurosci 31: 6277-6288.

Wohleb ES, Powell ND, Godbout JP, Sheridan JF (2013). Stress-induced recruitment of bone marrow-derived monocytes to the brain promotes anxietylike behavior. J Neurosci 33: 13820-13833. This study shows that social stress induces an increase in circulating monocytes and brain macrophages and the recruitment of peripheral myeloid cells within the perivascular space and parenchyma of stress-related brain regions.

Wright CL, McCarthy MM (2009). Prostaglandin E2-induced masculinization of brain and behavior requires protein kinase A, AMPA/kainate, and metabotropic glutamate receptor signaling. J Neurosci 29: 13274-13282.

Yamasaki R, Lu H, Butovsky O, Ohno N, Rietsch AM, Cialic R et al (2014). Differential roles of microglia and monocytes in the inflamed central nervous system. J Exp Med 211: 1533-1549.

Yang C, Shirayama Y, Zhang JC, Ren Q, Hashimoto K (2015). Peripheral interleukin-6 promotes resilience versus susceptibility to inescapable electric stress. Acta Neuropsychiatr 27: 312-316.

Yehuda R, Brand SR, Golier JA, Yang RK (2006). Clinical correlates of DHEA associated with post-traumatic stress disorder. Acta Psychiatr Scand 114: 187-193.

Yuen KW, Garner JP, Carson DS, Keller J, Lembke A, Hyde SA et al (2014). Plasma oxytocin concentrations are lower in depressed vs healthy control women and are independent of cortisol. J Psychiatr Res 51: 30-36.

Zhang D, Hu X, Qian L, O'Callaghan JP, Hong JS (2010). Astrogliosis in CNS pathologies: is there a role for microglia? Mol Neurobiol 41: 232-241.

Zhao QF, Tan L, Wang HF, Jiang T, Tan MS, Tan L et al (2016). The prevalence of neuropsychiatric symptoms in Alzheimer's disease: systematic review and metaanalysis. J Affect Disord 190: 264-271.

Zheng X, Ma S, Kang A, Wu M, Wang L, Wang Q et al (2016). Chemical dampening of Ly6C(hi) monocytes in the periphery produces anti-depressant effects in mice. Sci Rep 6: 19406. 